\title{
Kurtoxin, A Gating Modifier of Neuronal High- and Low-Threshold Ca Channels
}

\author{
Serguei S. Sidach and Isabelle M. Mintz \\ Department of Pharmacology and Experimental Therapeutics, Boston University Medical Center, Boston, \\ Massachusetts 02118
}

\begin{abstract}
Studies of Ca channels expressed in oocytes have identified kurtoxin as a promising tool for functional and structural studies of low-threshold T-type $\mathrm{Ca}$ channels. This peptide, isolated from the venomous scorpion Parabuthus transvaalicus, inhibits low-threshold $\alpha 1 \mathrm{G}$ and $\alpha 1 \mathrm{H}$ Ca channels expressed in oocytes with relatively high potency and high selectivity. Here we report its effects on Ca channel currents, carried by $5 \mathrm{~mm} \mathrm{Ba}^{2+}$ ions, in rat central and peripheral neurons. In thalamic neurons 500 nM kurtoxin inhibited T-type $\mathrm{Ca}$ channel currents almost completely $(90.2 \pm 2.5 \%$ at $-85 \mathrm{mV} ; n=6)$. Its selectivity, however, was less than expected because it also reduced the composite high-threshold $\mathrm{Ca}$ channel current recorded in these cells $(46.1 \pm 6.9 \%$ at $-30 \mathrm{mV} ; n=6)$. In sympathetic and thalamic neurons, 250-500 nм kurtoxin partially inhibited N-type and L-type $\mathrm{Ca}$ channel currents, respectively. It similarly reduced
\end{abstract}

the high-threshold $\mathrm{Ca}$ channel current that remains after a blockade of P-type, $\mathrm{N}$-type, and L-type Ca channels in thalamic neurons. In contrast, kurtoxin facilitated steady-state P-type Ba currents in Purkinje neurons (by $34.9 \pm 3.7 \%$; $n=10$ ). In all cases the kurtoxin effect was voltage-dependent and entailed a modification of channel gating. Exposure to kurtoxin slowed current activation kinetics, although its effects on deactivation varied with the channel types. Kurtoxin thus appears as a unique gating-modifier that interacts with different $\mathrm{Ca}$ channel types with high affinity. This unusual property and the complex gating modifications it induces may facilitate future studies of gating in voltage-dependent ion channels.

Key words: T-type Ca channel; $\omega$-Aga-IVA; Purkinje neuron; sympathetic neuron; thalamic neuron; high-threshold $\mathrm{Ca}$ channel
Peptide toxins derived from animal venoms have become valuable tools for studies of voltage-gated ion channels. Although the origin of these proteins may be diverse, their modes of action fall within two major categories. Pore-blocking toxins bind to the external vestibule of the channel pore and physically obstruct the movement of ions (MacKinnon and Miller, 1988). Gating modifiers bind close to the channel voltage sensor and alter the energetics of voltage-dependent gating (Cahalan, 1975). In the case of voltage-gated $\mathrm{Ca}$ channels, toxins that display high selectivity have been particularly useful. The pore blocker $\omega$-conotoxinGVIA ( $\omega$-CgTX) (Ellinor et al., 1994; Stocker et al., 1997), which inhibits N-type Ca channels (McCleskey et al., 1987) selectively (Aosaki and Kasai, 1989; Jones and Marks, 1989; Plummer et al., 1989), and the gating modifier $\omega$-Aga-IVA (Mintz et al., 1992a), which blocks P-type Ca channels with high affinity (Mintz et al., 1992b), have helped to characterize the gating behavior of these channels (Plummer et al., 1989; Usowicz et al., 1992; Tottene et al., 1996; Stocker et al., 1997), identify their structure (Williams et al., 1992; Sather et al., 1993; Berrow et al., 1997), and study their roles in controlling neuronal excitability (Llinás et al., 1989; Gorelova and Reiner, 1996; Magee and Carruth, 1999) and transmitter release (Pfrieger et al., 1992; Takahashi and Momiyama, 1993). These two toxins and others with less restricted selectivity (Hillyard et al., 1992; Lampe et al., 1993; McDonough et al., 1996)

\footnotetext{
Received April 30, 2001; revised Oct. 4, 2001; accepted Oct. 8, 2001.

This work was supported by National Institutes of Health Grant R01 NS36794. We thank Dr. Kenton J. Swartz for his generous gift of kurtoxin and helpf ul suggestions and Drs. Enrico Nasi and Abdul Traish for their comments on data analysis.

Correspondence should be addressed to Isabelle M. Mintz, Department of Pharmacology and Experimental Therapeutics, Boston University Medical Center, 80 East Concord Street, Boston, MA 02118. E-mail: imintz@bu.edu.

Copyright (C) 2002 Society for Neuroscience $0270-6474 / 02 / 222023-12 \$ 15.00 / 0$
}

also have been instrumental in defining important motifs in the voltage-sensing domain of high-threshold $\mathrm{Ca}$ channels (LiSmerin and Swartz, 1998) or in their pore region (Ellinor et al., 1994). As a result, a wealth of structural, biophysical, and functional data is available for high-threshold $\mathrm{Ca}$ channels.

In contrast, information on low-threshold $\mathrm{Ca}$ channels is still limited. T-type $\mathrm{Ca}$ channels play important roles that can be inferred from their voltage dependence and their characteristic activation, deactivation, and inactivation properties (Carbone and Lux, 1984). They may boost synaptic potentials (Hirsch et al., 1985), mediate Ca influx during action potentials (McCobb and Beam, 1991; Scroggs and Fox, 1992), and generate low-threshold Ca spikes (LTS) (Jahnsen and Llinás, 1984; Crunelli et al., 1989) and pacemaker activities (Destexhe et al., 1998), yet the lack of selective antagonist has limited the study of these roles (Huguenard, 1996).

After the recent cloning of T-type Ca channels (Lambert et al., 1998; Perez-Reyes et al., 1998; Lee et al., 1999), the screening of new inhibitors has led to the identification of a promising antagonist, kurtoxin (Chuang et al., 1998). This peptide acts with high selectivity on T-type Ca channels expressed in Xenopus oocytes. It inhibits low-threshold $\alpha 1 \mathrm{G}$ and $\alpha 1 \mathrm{H} \mathrm{Ca}$ channels potently but does not affect high-threshold $\alpha 1 \mathrm{~A}, \alpha 1 \mathrm{~B}, \alpha 1 \mathrm{C}$, and $\alpha 1 \mathrm{E} \mathrm{Ca}$ channels. Its selectivity, however, is not absolute, because kurtoxin also affects the inactivation of voltage-gated $\mathrm{Na}$ channels in oocytes (Chuang et al., 1998). Its effects on native ion channels have not yet been studied.

To characterize kurtoxin selectivity on neuronal Ca channels, we studied its effects on a variety of identified $\mathrm{Ca}$ channel currents in rat central and peripheral neurons. We found that these effects differed remarkably from those reported in oocytes. In 
neurons the kurtoxin interacted with high affinity with T-type, L-type, N-type, and P-type $\mathrm{Ca}$ channels, producing complex gating modifications that were specific to each channel type. This unique property will make it an asset for structural studies of gating in voltage-gated ion channels.

\section{MATERIALS AND METHODS}

Enzymatic dissociation of thalamic, sympathetic, and Purkinje neurons. Thalamic neurons from the ventral posteromedial (VPM) nucleus (Paxinos and Watson, 1986) were freshly dissociated with enzyme (Mintz et al., 1992b). Briefly, 400- $\mu$ m-thick coronal slices were cut in ice-cold Ringer's solution from brains of 10- to 13-d-old rats. The VPM nucleus was dissected out under $400 \times$ magnification. Then it was incubated for 8 min in a solution and maintained at $37^{\circ} \mathrm{C}$ under constant stirring, which contained (in mM): $81.4 \mathrm{Na}_{2} \mathrm{SO}_{4}, 30 \mathrm{~K}_{2} \mathrm{SO}_{2}, 5.8 \mathrm{MgCl}_{2}, 10 \mathrm{Na}$-HEPES, 20.4 glucose, $0.5 \%$ phenol red, $3 \mathrm{mg} / \mathrm{ml}$ protease type XXIII (Sigma, St. Louis, $\mathrm{MO}$ ), $\mathrm{pH} 7.4$, with $\mathrm{NaOH}$. After the incubation with enzyme, the brain tissue was rinsed three times in a MEM solution (reference 11090-073, Life Technologies, Grand Island, NY) supplemented with 20 mm glucose and $10 \mathrm{~mm}$ Na-HEPES, pH 7.4, with $\mathrm{NaOH}\left(\right.$ at $\left.37^{\circ} \mathrm{C}\right)$. Then cells were released by gentle trituration through a fire-polished Pasteur pipette into the MEM solution containing $20 \mathrm{~mm}$ glucose, $10 \mathrm{~mm} \mathrm{Na-}$ HEPES, $1 \mathrm{mg} / \mathrm{ml}$ trypsin inhibitor, and $1 \mathrm{mg} / \mathrm{ml}$ bovine serum albumin (Fraction V, Sigma), pH 7.4, with $\mathrm{NaOH}$. Cells were kept at $14-16^{\circ} \mathrm{C}$ and remained viable for 5-6 hr after preparation.

Purkinje neurons were dissociated from the cerebellar vermis of 9- to 11-d-old rats (Mintz et al., 1992b). The cerebellum was dissected out in ice-cold Ringer's solution and cut into three to four pieces, which were incubated with enzyme by following the protocol described above. After dissociation the Purkinje neurons were identified morphologically by their large cell bodies (15-25 $\mu \mathrm{m}$ in diameter) with single dendritic remnants.

Sympathetic neurons were prepared from 9- to 14-d-old rats (Boland et al., 1994; McDonough et al., 1997a). The superior cervical ganglia were dissected out in ice-cold oxygenated Leibovitz's L-15 medium (reference 11415-064, Life Technologies). Each ganglion was cut into two pieces before being incubated for $20 \mathrm{~min}$ at $37^{\circ} \mathrm{C}$ in a calcium-free Tyrode's solution that contained (in $\mathrm{mM}$ ): $150 \mathrm{NaCl}, 4 \mathrm{KCl}, 2 \mathrm{MgCl}_{2}, 10$ glucose, $10 \mathrm{Na}$-HEPES, 0.5 EDTA, and $2 \mathrm{~L}$-cysteine, $\mathrm{pH} 7.4$, with $\mathrm{NaOH}$, plus 25 $\mathrm{U} / \mathrm{ml}$ papain (Worthington Biochemicals, Lakewood, NJ). After this incubation the ganglia were transferred into calcium-free Tyrode's solution containing $1 \mathrm{mg} / \mathrm{ml}$ collagenase (type I) and $8 \mathrm{mg} / \mathrm{ml}$ dispase (Boehringer Mannheim, Indianapolis, IN). This incubation was performed at $37^{\circ} \mathrm{C}$ for $40 \mathrm{~min}$. The ganglia were rinsed three times, and the cells were released by gentle trituration into the MEM solution supplemented with $20 \mathrm{~mm}$ glucose, $10 \mathrm{~mm}$ Na-HEPES, $1 \mathrm{mg} / \mathrm{ml}$ trypsin inhibitor, and $1 \mathrm{mg} / \mathrm{ml}$ bovine serum albumin, $\mathrm{pH} 7.4$, with $\mathrm{NaOH}$ (at $37^{\circ} \mathrm{C}$ ).

Voltage-clamp recording. Patch-clamp recordings of $\mathrm{Ca}$ channel currents were performed in the whole-cell configuration (Hamill et al., 1981) by using $5 \mathrm{~mm} \mathrm{Ba}^{2+}$ ions as charge carrier. Patch pipettes were pulled from borosilicate glass capillaries (Fisher Scientific, Pittsburgh, PA), coated with Sylgard (Dow Corning, Midland, MI), and fire-polished to achieve a resistance of 1.5-2 $\mathrm{M} \Omega$ for recordings of Purkinje neurons and 3-3.5 $\mathrm{M} \Omega$ for recordings of thalamic and sympathetic neurons. In all of the recordings used in this report, the capacitance and access series resistance were compensated to minimize voltage errors to $<5 \mathrm{mV}$. From 3 to $10 \mathrm{G} \Omega$ seals were obtained routinely. We waited at least $5 \mathrm{~min}$ to allow the recording currents to stabilize. Ba currents usually ran down by $\sim 5-10 \%$ within the first 2 min of their recording. They stabilized within $5 \mathrm{~min}$, after which time rundown was negligible and the experiment was started. Current recordings are presented without leak correction. They were obtained with an Axopatch 200A patch-clamp amplifier (Axon Instruments, Foster City, CA). Voltage-step commands and data acquisition were controlled by using the external operation (XOP) Pulse Control (Herrington and Bookman, 1994) in IGOR Pro (WaveMetrics, Lake Oswego, OR) and the ITC-16 analog-to-digital converter from Instrutech (Port Washington, NY). In most experiments the currents were digitized at $100 \mu \mathrm{sec}$ and filtered at $2 \mathrm{kHz}$. For experiments focusing on tail currents, recordings were digitized at $20 \mu \mathrm{sec}$ and filtered at $10 \mathrm{kHz}$.

For data analysis and illustrations, we used IGOR Pro.

Statistics are given as mean \pm SEM.

Solutions. The solution in the recording pipette contained (in mM): 108 cesium methanesulfonate, $4 \mathrm{MgCl}_{2}$, 9 EGTA, 10 HEPES, $4 \mathrm{Mg}$-ATP, 0.3
GTP-Tris, 14 creatine phosphate (Tris salt), $\mathrm{pH} 7.3$, with $\mathrm{CsOH}$. The extracellular solution contained (in $\mathrm{mM}$ ): 160 tetraethylammonium (TEA)-chloride, $5 \mathrm{BaCl}_{2}, 10$ HEPES, 0.1 EGTA plus $1 \mu \mathrm{M}$ tetrodotoxin and $1 \mathrm{mg} / \mathrm{ml}$ cytochrome $c$, pH 7.4, with TEA-OH.

Stock solutions of $5 \mu \mathrm{M}$ kurtoxin (generously provided by Dr. K. J. Swartz, National Institute of Neurological Diseases and Stroke, National Institutes of Health, Bethesda, MD), $100 \mu \mathrm{M} \omega$-Aga-IVA (Peptide Institute, Osaka, Japan), $0.5 \mathrm{~mm} \omega$-conotoxin-GVIA (Peninsula Laboratories, San Carlos, CA), $100 \mu \mathrm{M}$ nimodipine, and $100 \mu \mathrm{M}$ Bay K 8644 (Research Biochemicals, Natick, MA) were prepared in the extracellular recording solution, aliquoted, and stored at $-80^{\circ} \mathrm{C}$. All other chemicals were purchased from Sigma.

The pipette tips, the recording chamber, and the vials that contain toxin stocks were all siliconized to minimize toxin loss via nonspecific binding.

Drug application and determination of kurtoxin potency. For most experiments the cells were recorded in a minichamber $(100 \mu \mathrm{l})$ to which small volumes of concentrated $(10 \times)$ toxin solution could be applied directly with a micropipette (Mintz et al., 1992b). With this protocol the recorded cells can be exposed to high concentrations of kurtoxin without using large amounts of toxin. Experiments investigating the kurtoxin inhibition of Bay K 8644-enhanced L-type Ba currents (see Fig. 7) and the $\mathrm{Ba}$ current that was resistant to blockers of P-type, L-type, and N-type Ca channels (see Fig. 8) were all performed in the minichamber (including studies of reversibility) to minimize the use of $\omega$-Aga-IVA and $\omega$-CgTX.

Although kurtoxin application to the minichamber allowed for reliable estimates of steady-state effects, it did not describe the kinetics of kurtoxin association accurately, because the toxin application was neither instantaneous nor homogenous. In most instances, current inhibition could not be fit with a monoexponential function. A number of experiments thus were performed by using a conventional array of gravity-fed glass microcapillaries $(100 \mu \mathrm{m}$ in diameter) that were connected with Teflon tubing to plastic syringes. Complete exchange of solution occurred within 1-2 sec, after the lateral displacement of the recorded cell from the opening of one capillary to the next. This application system was used to study the reversibility of kurtoxin effect on T-type (see Fig. $3 A$ ), P-type (see Figs. 4A2, 5), and N-type (see Fig. 6A1,A2) Ca channels. This application system also has limitations. It is difficult to ensure complete saturation of kurtoxin nonspecific binding sites to the glass capillaries. As for $\omega$-Aga-IVA, a prolonged perfusion (of $\sim 10 \mathrm{~min}$ ) of the glass capillary with the toxin-containing solution is necessary to saturate these binding sites. Because purified kurtoxin is not available in large quantities, most experiments were performed after a 2-4 min "loading" perfusion of the kurtoxin-containing solution. As a result, the time constants for current inhibition were overestimated, and it is possible that the current reduction measured in some experiments (see Figs. $4 A 2,6 A 2$ ) had not reached steady state.

These limitations account for the difference in kurtoxin potency when determined from the steady-state effects of kurtoxin (measured in the minichamber) and from the on-rate and off-rate time constants (measured by using microcapillaries).

All experiments were done at room temperature $\left(20-22^{\circ} \mathrm{C}\right)$.

\section{RESULTS}

\section{Kurtoxin inhibition of T-type and high-threshold Ba currents}

We investigated the effects of kurtoxin on identified T-type $\mathrm{Ca}$ channel currents recorded in thalamic neurons that were freshly isolated from the VPM nucleus. These bursting neurons display robust low-voltage-activated T-type calcium currents in addition to a composite high-threshold Ca channel current (Huguenard, 1996). In these cells test depolarizations elicited maximum T-type $\mathrm{Ca}$ channel currents when applied from a $-120 \mathrm{mV}$ holding potential (Kuo and Yang, 2001). At less negative holding potentials, measurable T-type current inactivation occurred. Nevertheless, because most cells constantly held at $-120 \mathrm{mV}$ became unstable over the 1-2 hr length of our recordings, we used a -80 $\mathrm{mV}$ holding potential and conditioned all test depolarizations with a 2-sec-long prepulse to $-120 \mathrm{mV}$. The amplitude and duration of this prepulse were sufficient to promote the complete 
recovery of inactivated T-type $\mathrm{Ca}$ channels. Longer or more negative prepulses had no additional effects on the amplitude of T-type Ca channel currents in these cells.

Consistent with its inhibition of low-threshold $\mathrm{Ca}$ channels expressed in oocytes (Chuang et al., 1998), $500 \mathrm{~nm}$ kurtoxin nearly abolished T-type Ba currents in thalamic neurons. Figure $1 A$ illustrates the low-threshold (left) and high-threshold (right) $\mathrm{Ca}$ channel currents carried by $5 \mathrm{~mm} \mathrm{Ba}$ in such a cell. The transient Ba current elicited by a $200 \mathrm{msec}$ depolarization to -75 $\mathrm{mV}$ was reduced by $\sim 90 \%$ after exposure to $500 \mathrm{~nm}$ kurtoxin. Current reduction was maximal because an increase in kurtoxin concentration to $1 \mu \mathrm{M}$ had no additional effect (Fig. $1 \mathrm{~A}$, left). The dose-response relationship (Fig. $1 C$ ) suggests a dissociation constant $\left(K_{\mathrm{D}}\right)$ for kurtoxin inhibition of thalamic T-type channels of $\sim 50$ nM.

Surprisingly, the composite high-threshold Ca channel current evoked in thalamic neurons by stronger depolarizations (Kammermeier and Jones, 1997) also was reduced by kurtoxin. Current inhibition was incomplete, however (Fig. $1 \mathrm{~A}$, right), and appeared to be less potent than that seen for T-type $\mathrm{Ca}$ channel currents. Although toxin concentrations of $500 \mathrm{nM}$ and $1 \mu \mathrm{M}$ were equally effective on low-threshold Ba currents (as seen in the $I-V$ relationship for test pulses below $-40 \mathrm{mV}$ ), $1 \mu \mathrm{M}$ kurtoxin produced greater inhibition of the high-threshold $\mathrm{Ba}$ currents triggered by test pulses above $-30 \mathrm{mV}$ (Fig. $1 B$ ).

\section{Selectivity}

The prominent effect of kurtoxin on the composite high-threshold $\mathrm{Ca}$ channel current of thalamic neurons suggests that this toxin may target multiple Ca channel types. We investigated this issue in rat Purkinje, sympathetic, and thalamic neurons by using pharmacological conditions that isolate large P-type, N-type, and L-type Ca channel currents, respectively.

Figure $2 A$ (left) illustrates the effects of kurtoxin on a Purkinje neuron P-type Ba current, which was recorded after a blockade of N-type and L-type Ca channels with $2.5 \mu \mathrm{M} \omega$-conotoxin-GVIA ( $\omega$-CgTX) and $2.5 \mu \mathrm{M}$ nimodipine (Mintz et al., 1992b). Kurtoxin had little effect on the peak current elicited by a $100 \mathrm{msec}$ test pulse to $-20 \mathrm{mV}$, but it slowed the kinetics of current activation remarkably. In a total of nine Purkinje neurons similarly exposed to $500 \mathrm{~nm}$ kurtoxin, the current that was measured $10 \mathrm{msec}$ after the onset of the test depolarization (applied from -80 to -20 $\mathrm{mV}$ ) amounted to $49.2 \pm 3.3 \%$ of the control current, whereas 90 msec later the current amplitude had returned to its control level $(94.8 \pm 1.9 \% ; n=9)$. Because kurtoxin produced minimal changes in steady-state current, we estimated the dose dependence of its effect by measuring the percentage of increase in the activation time constant of the Ba current elicited at the peak of the $I-V$ relationship $(\% \Delta \tau / \tau)$. The resulting dose-response curve (Fig. $2 A$, right) indicates a high-affinity interaction (estimated $K_{\mathrm{D}}$ of $\sim 15 \mathrm{~nm}$ ) between kurtoxin and Purkinje neuron P-type $\mathrm{Ca}$ channels.

In Figure $2 B$ (left), $500 \mathrm{~nm}$ kurtoxin partially inhibited a sympathetic neuron $\mathrm{N}$-type $\mathrm{Ca}$ channel current, which was recorded in isolation after a block of L-type Ca channels by $2.5 \mu \mathrm{M}$ nimodipine (Mintz et al., 1992b; Boland et al., 1994). Like Purkinje neuron P-type Ba currents, N-type Ba currents displayed slower activation kinetics in the presence of kurtoxin. Still, at steady state, current reduction remained significant, and it amounted to $46.9 \pm 1.2 \%$ of the control current (at $-10 \mathrm{mV} ; n=$ 10). Measurements of the peak current reduction for different concentrations of kurtoxin are represented in the dose-response
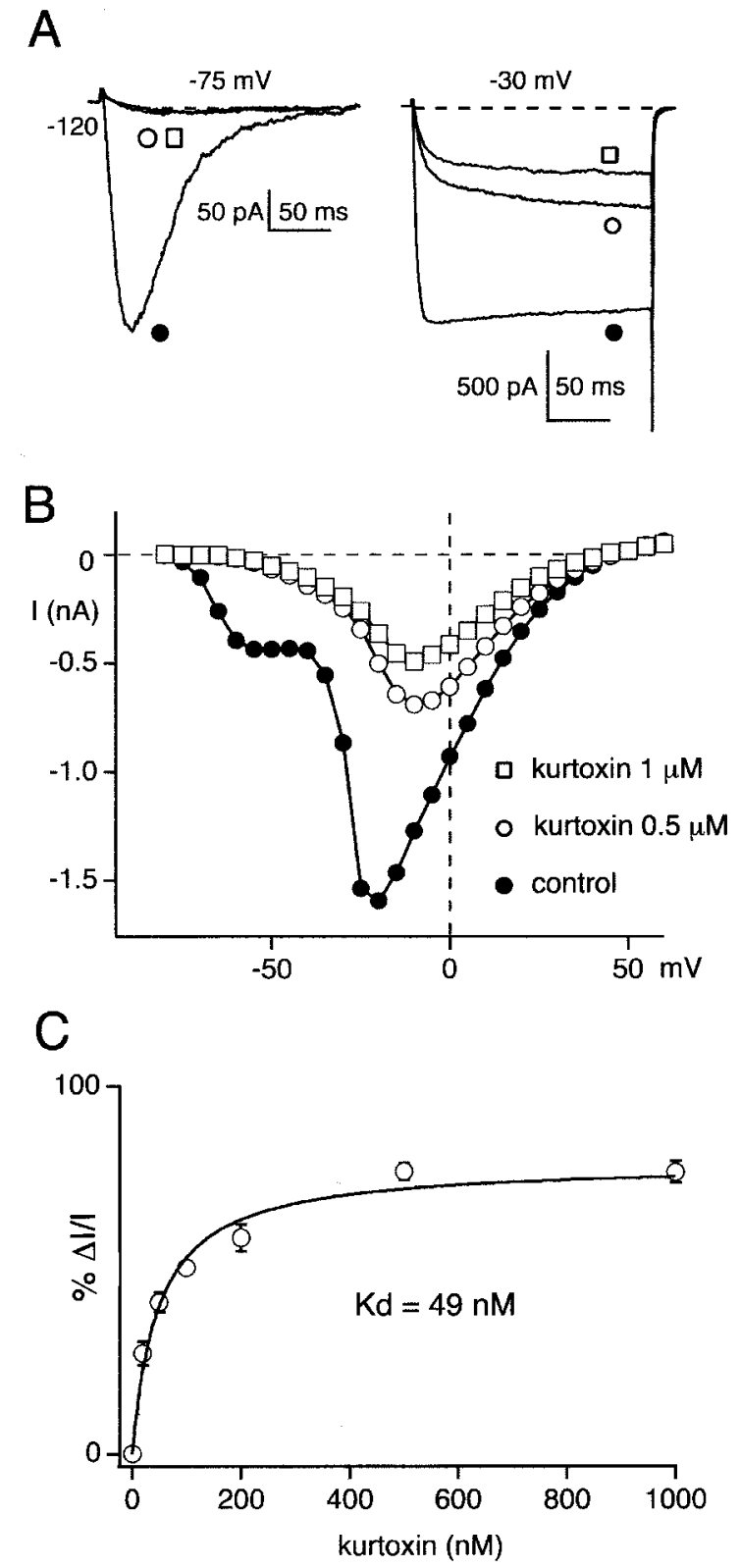

Figure 1. Kurtoxin inhibition of low-threshold and high-threshold Ca channel Ba currents in thalamic neurons. $A$, Ca channel currents carried by $5 \mathrm{mM} \mathrm{Ba}^{2+}$ were elicited by 200 -msec-long test depolarizations applied from -120 to $-75 \mathrm{mV}$ (left) or $-30 \mathrm{mV}$ (right) before (O) and after the application of $500 \mathrm{nM}(\bigcirc)$ and $1 \mu \mathrm{M}(\square)$ kurtoxin. B, Current-voltage relationships obtained in the same cell in control $(\bigcirc)$ and in the presence of $500 \mathrm{nM}(\bigcirc)$ and $1 \mu \mathrm{M}(\square)$ kurtoxin. Peak currents were measured during $200 \mathrm{msec}$ step depolarizations applied every $6 \mathrm{sec}$ from a holding potential of $-120 \mathrm{mV}$ to various test potentials (ranging from -80 to +50 $\mathrm{mV}$, in $5 \mathrm{mV}$ increments). $C$, Dose-response relationship for kurtoxin inhibition of T-type Ba currents recorded at $-50 \mathrm{mV}$ in thalamic neurons. Each data point represents the percentage of current reduction $(\% \Delta I / I)$ measured in $6-10$ cells (mean \pm SEM) for toxin concentrations below 1 $\mu \mathrm{M}$. Data quantifying the effects of $1 \mu \mathrm{M}$ kurtoxin were obtained from three cells. The data were fit with a hyperbolic function, with $K_{\mathrm{D}}=49 \mathrm{~nm}$ and $[\Delta I / I] \max =80 \%$.

curve of Figure $2 B$ (right). Kurtoxin inhibition of $\mathrm{N}$-type $\mathrm{Ca}$ channels appeared to be notably weaker (estimated $K_{\mathrm{D}}$ of $\approx 450$ nM) than its effects on T-type and P-type Ca channels.

We assessed the sensitivity of L-type Ca channels to $500 \mathrm{~nm}$ kurtoxin in thalamic neurons (Fig. 2C). To maximize the contri- 


\section{A P-type Ba current}

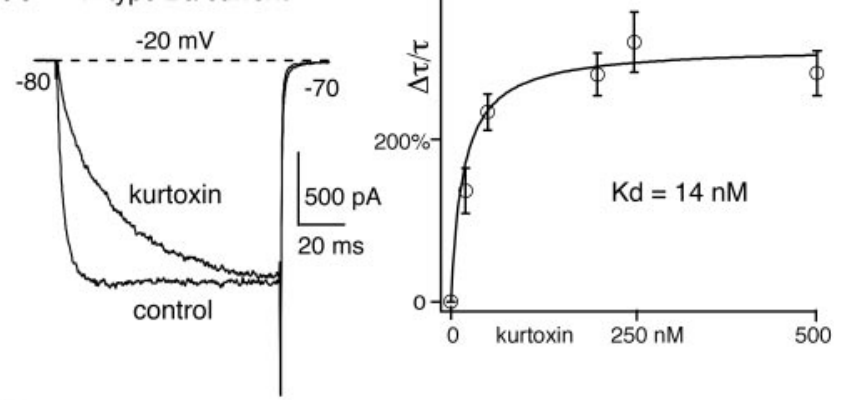

B N-type Ba current
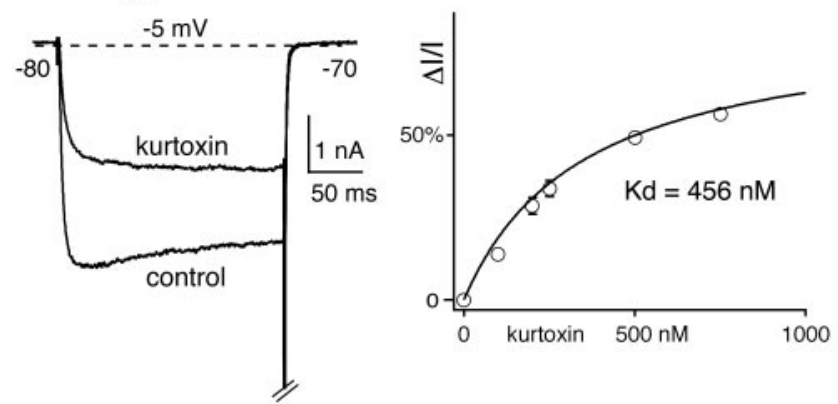

C L-type Ba current
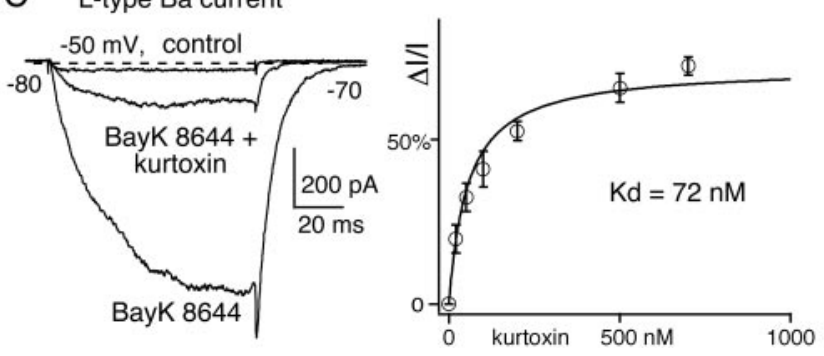

Figure 2. Kurtoxin modulation of neuronal P-type, N-type, and L-type Ba currents. A, Left, In a Purkinje neuron the P-type Ba current was evoked by a $100 \mathrm{msec}$ depolarization applied from -80 to $-20 \mathrm{mV}$ before and after the application of $500 \mathrm{~nm}$ kurtoxin. Nimodipine $(2.5 \mu \mathrm{M})$ and $\omega$-CgTX $(2.5 \mu \mathrm{M})$ were present throughout the experiment. Right, The dose-response relationship for kurtoxin modulation of P-type Ba currents in Purkinje neurons. Each data point represents the percentage of increase in the time constant of current activation recorded at the peak of the $I-V$ relationship after exposure to increasing concentrations of kurtoxin (mean $\pm \mathrm{SEM} ; n=8$ or 9 for each data point). The data were fit with a hyperbolic function, with $K_{\mathrm{D}}=14 \mathrm{~nm}$ and $[\Delta \tau / \tau] \max =308 \%$. B, Left, In a sympathetic neuron, N-type Ba current evoked by a $200 \mathrm{msec}$ depolarization was applied from -80 to $-5 \mathrm{mV}$ before and after $500 \mathrm{~nm}$ kurtoxin application. Nimodipine $(2.5 \mu \mathrm{M})$ was present throughout the experiment. $B$, Right, Dose-response relationship for kurtoxin inhibition of $\mathrm{N}$-type $\mathrm{Ba}$ currents in sympathetic neurons. Each data point represents the percentage of current reduction $(\% \Delta I / I)$ measured at $-10 \mathrm{mV}$ after exposure to increasing concentrations of kurtoxin (mean \pm SEM; $n=3,6,15,17$, and 3 for $100,200,250,500$, and $750 \mathrm{~nm}$ toxin concentrations, respectively). The data were fit with a hyperbolic function, with $K_{\mathrm{D}}=456 \mathrm{nM}$ and $[\Delta I / I] \max =95 \%$. C, Left, In a thalamic neuron, L-type Ba current evoked by a $100 \mathrm{msec}$ depolarization was applied from -80 to $-50 \mathrm{mV}$ in control conditions, after the application of $3 \mu \mathrm{M}$ Bay K 8644, and in the presence of $500 \mathrm{~nm}$ kurtoxin plus $3 \mu \mathrm{M}$ Bay K 8644. $\omega$-CgTX $(2.5 \mu \mathrm{M})$ and $\omega$-Aga-IVA (200 nM) were present throughout the experiment. C, Right, Dose-response relationship for kurtoxin inhibition of Bay K 8644enhanced L-type Ba currents, recorded as in $B$ (left) at $-50 \mathrm{mV}$ and in the continuous presence of $\omega$-CgTX $(2.5 \mu \mathrm{M})$ and $\omega$-Aga-IVA (100 nM). Each data point represents the percentage of current reduction $(\% \Delta I / I$; mean \pm SEM; $n=3$ or 4 ) produced by each concentration of kurtoxin. The data were fit with a hyperbolic function, with $K_{\mathrm{D}}=72 \mathrm{nM}$ and $[\Delta I / I] \max =78 \%$. In all of the experiments in $A-C$ the currents were carried by $5 \mathrm{~mm} \mathrm{Ba}^{2+}$ ions, and tail currents were recorded at $-70 \mathrm{mV}$. bution of L-type Ca channels to the recorded currents, we performed experiments after a block of N-type and P-type $\mathrm{Ba}$ currents with $2.5 \mu \mathrm{M} \omega$-CgTX and $200 \mathrm{~nm} \omega$-Aga-IVA and after enhancement of L-type Ca channel currents with the dihydropyridine agonist Bay K 8644 (3 $\mu \mathrm{M}$ ) (Hess et al., 1984; Nowycky et al., 1985). In the continuous presence of $\omega$-CgTX and $\omega$-AgaIVA the application of Bay K 8644 resulted in a 10- to 15-fold facilitation of the small $\mathrm{Ba}$ current elicited by depolarizations to $-50 \mathrm{mV}$, indicating that this current was carried primarily through L-type $\mathrm{Ca}$ channels with little contamination from other high-threshold Ca channels (Fig. 2C, left). Bay K 8644 also induced a pure L-type $\mathrm{Ca}$ channel tail current, which deactivated with slow kinetics, consistent with a prolongation of the open time of these channels (Nowycky et al., 1985). On average, 500 nм kurtoxin inhibited Bay K 8644-enhanced L-type Ca channel currents by $74.1 \pm 3.7 \%$ (current reduction measured at $-50 \mathrm{mV}$; $n=6)$. The dose-response curve illustrated in Figure $2 C$ (right), which was obtained in the same recording conditions, shows that kurtoxin inhibition of thalamic L-type Ba currents is potent, with an estimated $K_{\mathrm{D}}$ of $\sim 70 \mathrm{~nm}$.

These results demonstrate that kurtoxin affected each Ca channel type (T-type, L-type, N-type, and P-type) that can be identified pharmacologically in mammalian neurons. Surprisingly, P-type and N-type channels, which are most alike structurally, showed dramatically different responses to kurtoxin. These differences motivated a detailed investigation of kurtoxin actions on T-type, P-type, N-type, and L-type Ca channel currents.

\section{Kurtoxin inhibition of T-type Ba currents Reversibility}

In thalamic neurons the kurtoxin inhibition of T-type $\mathrm{Ca}$ channel currents was fully reversible (Fig. $3 A$, left; $n=6$ ). In the experiment of Figure $3 A$, a saturating concentration of $500 \mathrm{~nm}$ kurtoxin inhibited T-type $\mathrm{Ca}$ channel current recorded at $-60 \mathrm{mV}$ by $\sim 77 \%$ within $60 \mathrm{sec}$ of its application. With toxin removal the current fully recovered to its control value within $100 \mathrm{sec}$. Both current inhibition and current recovery followed monoexponential time courses ( $\tau_{\text {on }}=6.7$ and $\tau_{\text {off }}=13 \mathrm{sec}$ for $500 \mathrm{~nm}$ kurtoxin).

\section{Gating modifications}

Within the range of membrane potentials $(-85$ to $-60 \mathrm{mV})$, in which T-type $\mathrm{Ca}$ channels activated with little contamination from high-threshold $\mathrm{Ca}$ channels, the magnitude of T-type current inhibition by kurtoxin appeared to be voltage-dependent. Although kurtoxin abolished the Ba current elicited at $-85 \mathrm{mV}$, the magnitude of this effect decreased when currents were triggered by larger test depolarizations (Fig. 3B). For example, T-type Ba currents measured at $-60 \mathrm{mV}$ were inhibited by only $55.3 \pm 2.6 \%(n=11)$.

At all test voltages kurtoxin also slowed the current activation and inactivation. This is illustrated in Figure $3 C$ by superimposed, normalized T-type $\mathrm{Ba}$ currents recorded before and after the addition of $500 \mathrm{~nm}$ kurtoxin. Kurtoxin increased the current activation and inactivation time constants (measured at $-60 \mathrm{mV}$ ) by similar factors (of 2.6 and 2.1, respectively; $n=10$ ). Kurtoxin also increased the rate of current deactivation (Fig. $3 D$ ). This was seen best when tail currents were recorded at $-110 \mathrm{mV}$ to minimize current inactivation (Kuo and Yang, 2001). Normalized tail currents recorded before and after the addition of kurtoxin showed a clear increase in their rate of deactivation $(n=4)$. Because they were poorly fit with single exponentials, we used the 
A

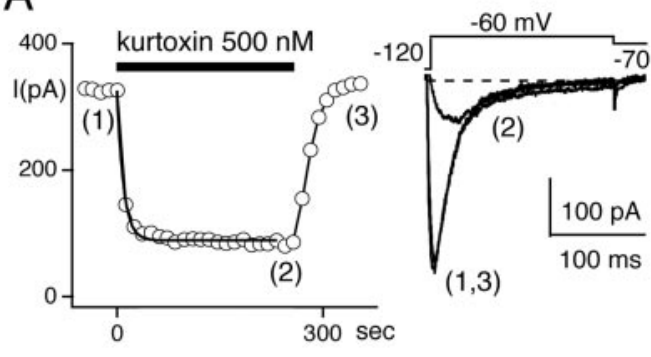

B
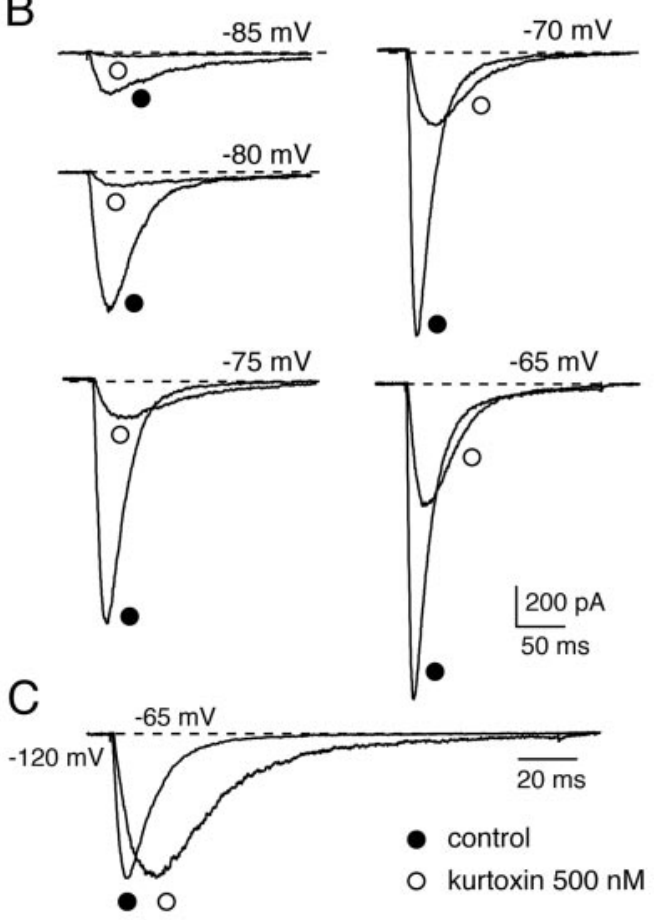

D

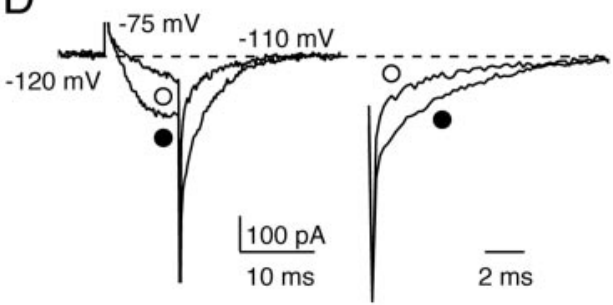

Figure 3. Kurtoxin inhibition of thalamic T-type Ba currents. A, Left, Low-threshold T-type Ba currents elicited by $200 \mathrm{msec}$ depolarizations to $-60 \mathrm{mV}$ in control conditions (1), after the application of $500 \mathrm{~nm}$ kurtoxin (2), and $90 \mathrm{sec}$ after toxin removal (3). Data points (right) represent the peak current versus time in the same cell. The thick line is a monoexponential fit $\left(\tau_{\text {on }}=6.7 \mathrm{sec}\right)$. $B$, In another thalamic neuron shown is the kurtoxin inhibition of T-type Ba currents elicited by 200 msec depolarizations of increasing amplitude ( -85 to $-65 \mathrm{mV}$ range, in $5 \mathrm{mV}$ increments). Currents were recorded in control conditions $(\bullet)$ and after a 5 min incubation with $500 \mathrm{~nm}$ kurtoxin $(\bigcirc)$. $C$, Normalized Ba currents elicited by a $200 \mathrm{msec}$ depolarization to $-65 \mathrm{mV}$ before $(\bullet)$ and after $(\bigcirc)$ the application of $500 \mathrm{~nm}$ kurtoxin (same cell as B). D, Left, Kurtoxin effect on T-type tail currents recorded at $-110 \mathrm{mV}$ after a 10 msec test pulse to $-75 \mathrm{mV}$ before $(\bullet)$ and after $(\bigcirc)$ the application of 500 nM kurtoxin. These tail currents were normalized for comparison on the right. For all of the experiments in $A-D$ the currents were carried by $5 \mathrm{~mm}$ $\mathrm{Ba}^{2+}$ ions; tail currents (except in $D$ ) were recorded at $-70 \mathrm{mV}$, and the cells were held at a $-80 \mathrm{mV}$ holding potential. To promote $\mathrm{T}$-type $\mathrm{Ca}$ channel recovery from inactivation, we applied a 2-sec-long hyperpolarization to $-120 \mathrm{mV}$ before each test depolarization. later phase of deactivation to quantify this effect $\left(\tau_{\text {cont }}=3.6\right.$ and $\tau_{\text {kurt }}=2.8$ msec; Fig. $3 D$ ).

\section{Kurtoxin facilitation of P-type Ba currents}

Figure 4 illustrates kurtoxin effects on P-type Ba currents in Purkinje neurons. To suppress the small current fractions that flow through $\mathrm{N}$-type and L-type $\mathrm{Ca}$ channels in these cells, we recorded currents in the continuous presence of $2.5 \mu \mathrm{M}$ each $\omega$-CgTX and nimodipine. As already seen in Figure 2A, $500 \mathrm{~nm}$ kurtoxin altered the activation kinetics of $\mathrm{P}$-type $\mathrm{Ca}$ channel significantly. In Purkinje neurons that were recorded in these conditions $(n=9)$, current activation (measured at $-15 \mathrm{mV})$ was well described by a single exponential in control $(\tau=1.2 \pm 0.1$ $\mathrm{msec})$ and after exposure to kurtoxin $(\tau=4.8 \pm 0.5 \mathrm{msec})$.

\section{Reversibility}

To monitor the time course of kurtoxin action (Fig. 4A2), we chose to measure current amplitude $5 \mathrm{msec}$ after the onset of the test pulse to $-15 \mathrm{mV}$, because kurtoxin had little effect on the steady-state current amplitude (Fig. 4A1). The effect of $500 \mathrm{~nm}$ kurtoxin on P-type $\mathrm{Ca}$ channel currents was relatively fast and readily reversible $(n=6)$. In the experiment of Figure $4 A 2$ the time course of current reduction was well described by a single exponential function $\left(\tau_{\text {on }}\right.$ of $\approx 12 \mathrm{sec}$ ). Removal of the toxin led to rapid and complete current recovery, which followed a monoexponential time course ( $\tau_{\text {off }}$ of $\approx 51 \mathrm{sec}$ ).

In many cells the current recovered after toxin removal was bigger than in control conditions (Fig. 4A1, trace 3). Such current run-up is not specific to kurtoxin. Often it is seen when P-type Ba currents in Purkinje neurons recover from a block by $\omega$-Aga-IVA (Mintz et al., 1992b) or Cd ions (I. M. Mintz, unpublished results).

\section{Current facilitation}

Kurtoxin facilitated the P-type Ba currents measured at steady state during large test depolarizations (Fig. 4B,C1-C3) while it reduced the currents elicited by smaller test pulses. These effects are illustrated by the $I-V$ relationships presented in Figure $4 C 2$ and the corresponding activation curves in Figure 4C3. The latter were well described by single Boltzmann distributions. They showed that kurtoxin shifted the voltage for half-maximum activation $\left(V_{1 / 2}\right)$ toward positive potentials by $2.4 \pm 0.54 \mathrm{mV}(n=9)$ and did not affect the curve slope factor. This shift in $V_{1 / 2}$ may reflect an inhibition of P-type $\mathrm{Ca}$ channel current during small test pulses (because toxin-bound channels require larger depolarization to open) but also, to some extent, an artifact. In the presence of kurtoxin the slowly activating currents recorded at the foot of the $I-V$ relationship may not have reached steady state within the duration of the test pulses $(20 \mathrm{msec})$.

The facilitation of P-type Ba currents during large test depolarizations was accompanied with a parallel enhancement of the tail currents seen on repolarization. In Purkinje neurons that were exposed to $500 \mathrm{~nm}$ kurtoxin, the tail currents were consistently larger (by $34.9 \pm 3.7 \% ; n=10$ ) and slower (see the normalized tail currents in the inset, Fig. $4 B$ ) than in control conditions. The effect on tail current deactivation was fully reversible (Fig. 4A1). These findings suggest that kurtoxin facilitation of P-type Ca channels is mediated, at least partially, by an increase in the channel open time, confirming that kurtoxin is a gating modifier of P-type $\mathrm{Ca}$ channels.

It has been proposed that gating modifiers recognize a conserved binding motif in voltage-gated ion channels (Li-Smerin 
A1

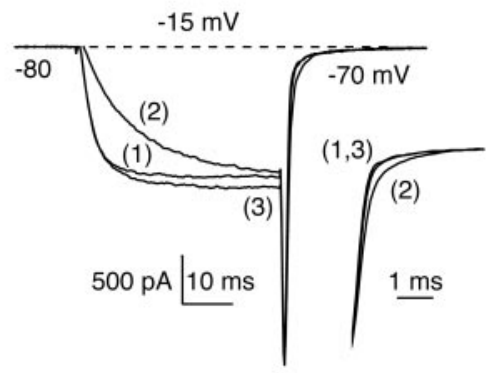

C1

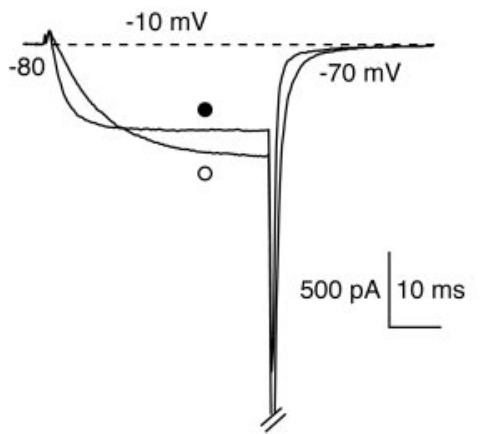

A2

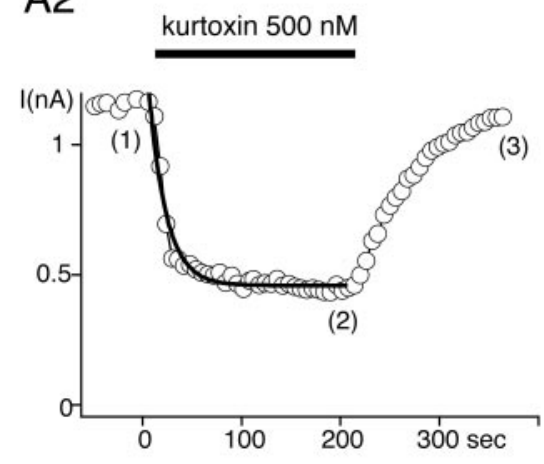

C2

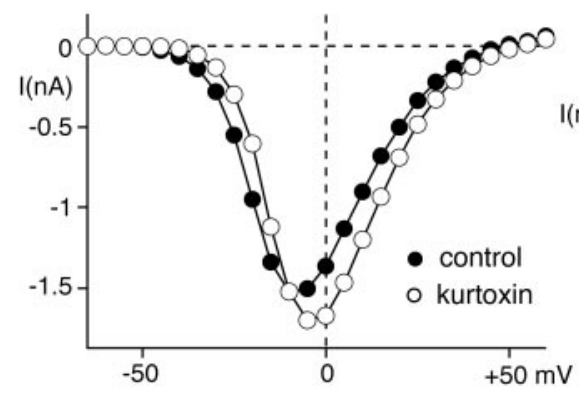

B

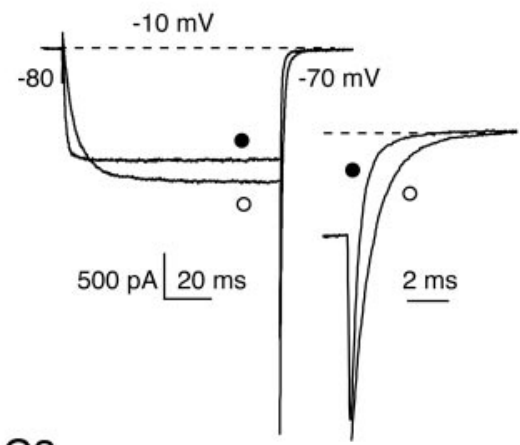

C3

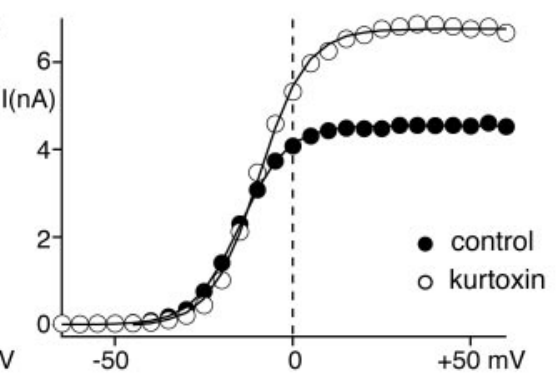

Figure 4. Kurtoxin facilitation of Purkinje neuron P-type Ba currents. A1, A2, P-type Ba currents (A1) evoked by a 20 msec depolarization applied from -80 to $-15 \mathrm{mV}$ in control conditions (1), after $500 \mathrm{~nm}$ kurtoxin application (2), and after complete washout of the toxin (3). Because the peak Ba current during a $20 \mathrm{msec}$ depolarization was similar to its control value, the data points in $A 2$ represent the Ba current, measured early in the test pulse (at 5 $\mathrm{msec})$ versus time. The thick line illustrates a monoexponential fit $\left(\tau_{\mathrm{on}}=12 \mathrm{sec}\right) . B$, In another Purkinje neuron, kurtoxin facilitation of P-type Ba current was elicited by a $100 \mathrm{msec}$ depolarization from -80 to $-10 \mathrm{mV}$. The inset illustrates the normalized tail currents recorded at $-70 \mathrm{mV}$ before $(\mathbf{})$ and after $(\bigcirc)$ exposure to $500 \mathrm{~nm}$ kurtoxin. $C 1-C 3$, Kurtoxin effects on the activation properties of P-type Ba currents. C1, P-type Ba current elicited by a $20 \mathrm{msec}$ depolarization from -80 to $-5 \mathrm{mV}$ before $(\bullet)$ and after $(\bigcirc)$ the application of $500 \mathrm{~nm}$ kurtoxin. C2, Current-voltage relationships obtained in the same cell before and after the application of kurtoxin. The data points represent the peak current during 20-msec-long depolarizations, which were applied every $6 \mathrm{sec}$ from a holding potential of $-80 \mathrm{mV}$ to various test potentials (ranging from -75 to $+50 \mathrm{mV}$, in $5 \mathrm{mV}$ increments). C3, Corresponding activation curves represent, as a function of test potentials, the amplitude of the tail currents recorded at $-70 \mathrm{mV}$ before and after kurtoxin application. Each curve was fit by using a single Boltzmann distribution: $\left[I=I_{\max } /\left(1+\exp \left[-\left(V-V_{\mathrm{h}}\right) / k\right]\right)\right]$, with $V_{\mathrm{h}}=-14.8 \mathrm{mV}$ and $k=6.5 \mathrm{mV}-1$ in control conditions and $V_{\mathrm{h}}=-9.7 \mathrm{mV}$ and $k=6.7 \mathrm{mV}^{-1}$ after kurtoxin application. All of the experiments in $A 1-C 3$ were performed in the continuous presence of $2.5 \mu \mathrm{M}$ nimodipine and $2.5 \mu \mathrm{M} \omega$-CgTX.

and Swartz, 1998), suggesting that kurtoxin and $\omega$-Aga-IVA, two gating modifiers of $\mathrm{P}$-type $\mathrm{Ca}$ channels, might interact at the same binding site. To test this hypothesis, we investigated how kurtoxin affects $\omega$-Aga-IVA inhibition of P-Type Ba currents in Purkinje neurons.

\section{Kurtoxin and $\omega$-Aga-IVA binding sites}

Because the effects of kurtoxin and $\omega$-Aga-IVA on P-type Ca channels are fully reversible, we were able to assess, in the same cell, the inhibition of P-type Ba currents by $\omega$-Aga-IVA when it was applied alone or in the presence of kurtoxin. In the experiment of Figure 5, the application of $500 \mathrm{~nm}$ kurtoxin did not affect the amplitude of the peak current that was elicited by a $20 \mathrm{msec}$ test depolarization to $-20 \mathrm{mV}$ (Fig. $5 A$ ). The progression of its effect was signaled, however, by changes in current activation (Fig. 5B). After kurtoxin effect had reached steady state, the coapplication of $200 \mathrm{~nm} \omega$-Aga-IVA led to a slow $\left(\tau_{\text {on }}\right.$ of $\left.\approx 60 \mathrm{sec}\right)$ and partial inhibition of P-type Ba currents (Fig. $5 C$ ). This result is very different from the complete and rapid reduction of P-type Ba currents normally produced by $200 \mathrm{~nm} \omega$-Aga-IVA in Purkinje neurons. Indeed, on washout of both toxins and complete current recovery (which was facilitated by the administration of 39 pulses to $+140 \mathrm{mV}$ ), the application of $200 \mathrm{~nm} \omega$-Aga-IVA rapidly abolished the recovered P-type Ba current $\left(\tau_{\text {on }}\right.$ of $\approx 12$ sec; Fig. 5C).

These findings are consistent with overlapping binding sites for kurtoxin and $\omega$-Aga-IVA in P-type Ca channels.

\section{Kurtoxin inhibition of $\mathrm{N}$-type Ba currents}

Figure 6 illustrates the characteristics of N-type $\mathrm{Ca}$ channel current inhibition by kurtoxin. For these studies the Ba currents carried through $\mathrm{N}$-type $\mathrm{Ca}$ channels were isolated in rat sympathetic neurons after a block of L-type Ca channels with $2.5 \mu \mathrm{M}$ nimodipine (Boland et al., 1994).

\section{Current block and recovery exhibit complex kinetics}

Kurtoxin (500 nM) inhibition of N-type Ba currents in sympathetic neurons followed complex kinetics that were well described by a dual exponential time course, with fast $\left(\tau_{\text {fast }}=13 \mathrm{sec}\right)$ and slow $\left(\tau_{\text {slow }}=247 \mathrm{sec}\right)$ components (Fig. 6A2). The fast component was predominant, because $\sim 80 \%$ of the total current inhibition occurred within $60 \mathrm{sec}$ of the toxin application.

With the removal of kurtoxin the current recovery was incomplete $(n=12)$. In the experiment of Figure $6 A 2$, the current elicited at $-5 \mathrm{mV}$ recovered to $\sim 80 \%$ of its control value, after a simple monoexponential time course, with a time constant $\tau_{\text {off }}$ of 


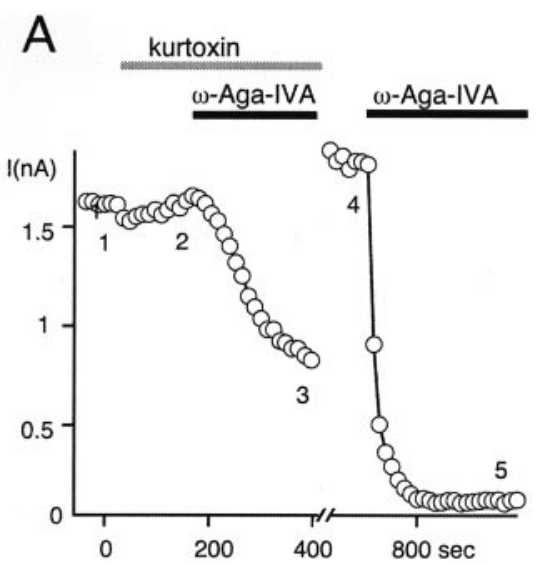

B

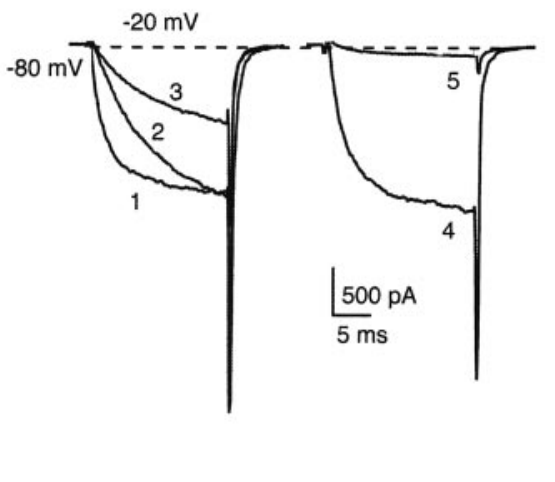

C

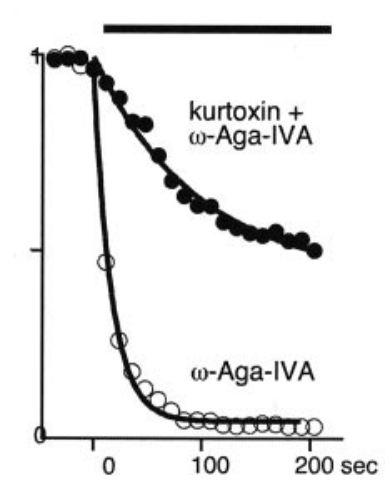

Figure 5. Kurtoxin interference with $\omega$-Aga-IVA inhibition of P-type Ba currents in a Purkinje neuron. A, Time course of P-type Ba current inhibition by $200 \mathrm{~nm} \omega$-Aga-IVA applied alone or in the presence of $500 \mathrm{~nm}$ kurtoxin. The data points represent the peak current during a 20 msec depolarization applied from -80 to $-20 \mathrm{mV}$ every $6 \mathrm{sec}$. First the recorded cell was exposed to 500 nm kurtoxin and, after kurtoxin effect had reached steady state, to the combined application of $200 \mathrm{nM} \omega$-Aga-IVA plus $500 \mathrm{~nm}$ kurtoxin for $5 \mathrm{~min}$. Then both toxins were washed out. To facilitate current recovery, we applied three trains of large depolarizations. Each train (315 msec long) consisted of 13 test pulses (each $15 \mathrm{msec}$ long) to +140 mV. After current stabilization, $200 \mathrm{nM} \omega$-Aga-IVA was reapplied. $B$, Representative current traces from the same experiment at the different times (1-5) indicated in $A$. $C$, Normalized time courses of the peak Ba currents recorded, in the same experiment, during the application of $200 \mathrm{~nm} \omega$-Aga-IVA $(O)$ or during the coapplication of $200 \mathrm{~nm} \omega$-Aga-IVA and $500 \mathrm{~nm}$ kurtoxin $(\bullet)$. The thick lines represent exponential fits of the data, with $\tau_{\mathrm{on}}=12 \mathrm{sec}(\mathrm{O})$ and $\tau_{\mathrm{on}}=60$ sec (). All recordings in $A-C$ were obtained from the same cell.

$\mathrm{A} 1$
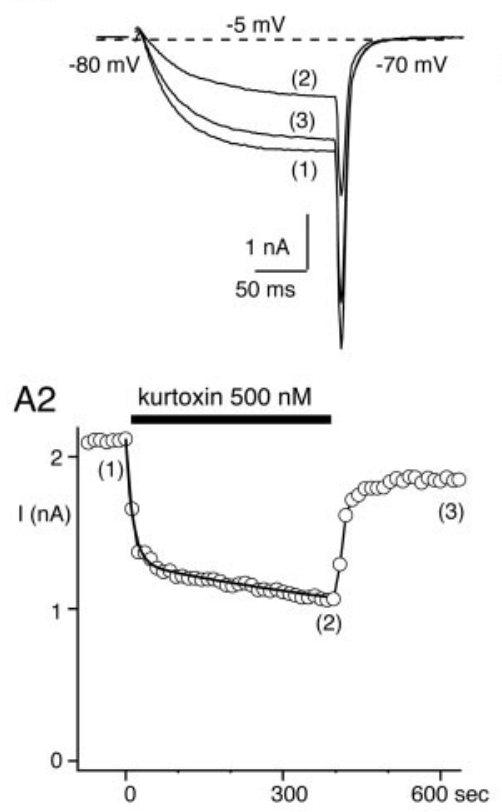

B

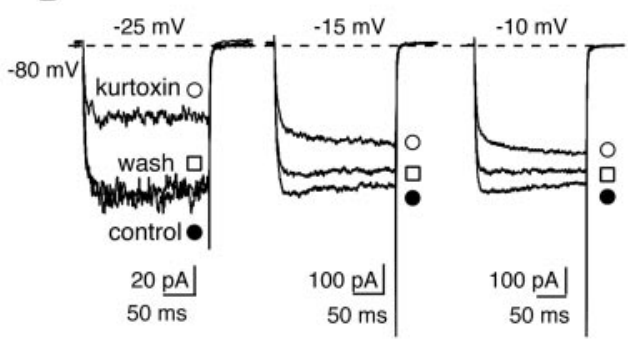

C

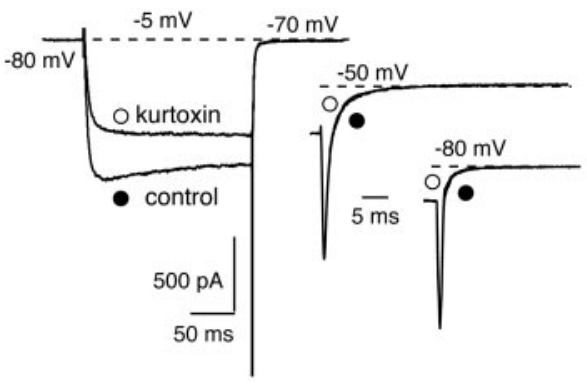

D1

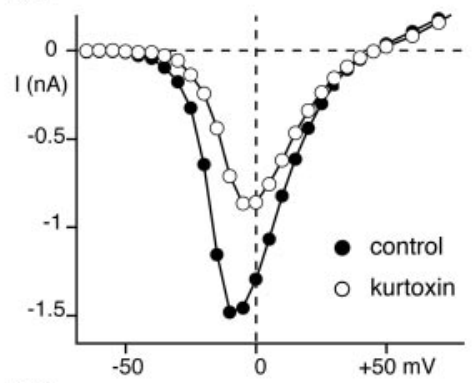

D2

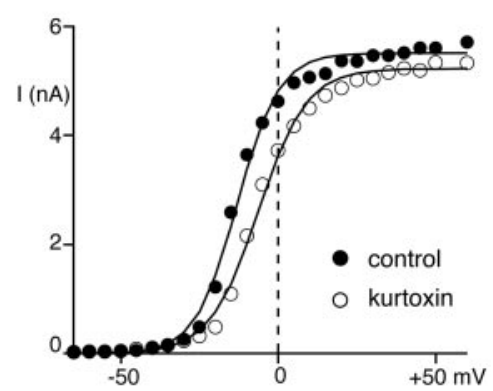

Figure 6. Kurtoxin inhibition of N-type Ba currents in sympathetic neurons. A1, N-type Ba currents elicited by 20 msec depolarizations applied from -80 to $-5 \mathrm{mV}$ in control conditions (1), after exposure to $500 \mathrm{~nm}$ kurtoxin (2), and 2 min after kurtoxin removal (3). A2, Corresponding time course in the same cell, representing the peak Ba current elicited by test pulses applied every $6 \mathrm{sec}$, to $-5 \mathrm{mV}$. The two thick lines represent a dual exponential fit of current inhibition $\left(\tau_{\text {fast }}=13\right.$ and $\left.\tau_{\text {slow }}=247 \mathrm{sec}\right)$ and a monoexponential fit for current recovery $\left(\tau_{\text {off }}=20 \mathrm{sec}\right)$. $B$, In a different sympathetic neuron shown are the Ba currents elicited by 200-msec-long depolarizations applied from -80 to $-25,-15$, and $-10 \mathrm{mV}$ test potentials in control conditions ( $(\bullet)$, in the presence of $500 \mathrm{~nm}$ kurtoxin $(\bigcirc)$, and 2 min after the removal of kurtoxin $(\square)$. C, N-type Ba currents elicited by a 100-msec-long test depolarization from -80 to $-5 \mathrm{mV}$ before $(\bullet)$ and after $(\bigcirc)$ the application of $500 \mathrm{~nm}$ kurtoxin. The insets illustrate the normalized tail currents that were recorded at -50 or at $-80 \mathrm{mV}$ after the same test depolarization. $D 1, D 2$, Current-voltage relationship $(D 1)$ and corresponding activation curve $(D 2)$ in a sympathetic neuron before and after the application of $500 \mathrm{~nm}$ kurtoxin. The data points illustrate the peak Ba current $(D 1)$ or the tail current $(D 2)$ measured, respectively, during or after $50 \mathrm{msec}$ depolarizations applied from $-80 \mathrm{mV}$ to increasing test potentials. The tail currents were recorded at $-70 \mathrm{mV}$. The activation curves in $D 2$ were fit with single Boltzmann distributions, using $V_{\mathrm{h}}=-8.0 \mathrm{mV}$ and $k=6.6 \mathrm{mV}^{-1}$ in control conditions and $V_{\mathrm{h}}=-1.3 \mathrm{mV}$ and $k=7.7 \mathrm{mV}-1$ after kurtoxin application. All of the experiments in $A 1-D 2$ were performed in the continuous presence of $2.5 \mu \mathrm{M}$ nimodipine. 
$\sim 20$ sec. Because we selected cells with very stable control currents for these experiments, the current fraction that did not recover after wash of the toxin likely reflected irreversible current inhibition by kurtoxin rather than current rundown.

Interestingly, current recovery was more complete when currents were recorded at potentials below $-20 \mathrm{mV}(n=6)$. In Figure $6 B$, the N-type Ba current elicited by a small test depolarization returned to its control level after washout of the toxin (Fig. 6B, left). In the same cell, after the same duration of wash, the currents elicited by larger depolarizations recovered only partially, by $\sim 70 \%$ at $-15 \mathrm{mV}$ (Fig. $6 B$, middle) and by $\sim 60 \%$ at $-10 \mathrm{mV}$ (Fig. 6B, right).

\section{Gating modifications}

Kurtoxin reduction of $\mathrm{N}$-type $\mathrm{Ca}$ channel currents in sympathetic neurons also was accompanied by a slowing of activation (Fig. $6 A 1, B, C)$. On average, the activation time constant of currents recorded at $-10 \mathrm{mV}$ was $2.34 \pm 0.07 \mathrm{msec}$ in control conditions and $3.42 \pm 0.07 \mathrm{msec}$ in the presence of $500 \mathrm{~nm}$ kurtoxin $(n=10)$. Interestingly, there was no apparent change in deactivation. In Figure $6 C$, tail currents were measured after a test pulse to -5 $\mathrm{mV}$ at different repolarizing potentials $(-80,-70$, and $-50 \mathrm{mV})$. After normalization the tail currents recorded before and after kurtoxin application were, in each case, identical.

The magnitude of kurtoxin effect on N-type Ba currents was voltage-dependent. In the $I-V$ relationships of Figure $6 D 1$, larger current reduction occurred at more negative test potentials. For example, kurtoxin inhibited $39.3 \pm 1.8 \%$ of the peak current measured at $-10 \mathrm{mV}$ and only $25.4 \pm 1.7 \%$ of that evoked at +10 $\mathrm{mV}(n=10)$. Although activation curves recorded in control conditions were poorly fit by single Boltzmann distributions (Fig. 6D2), they consistently showed a slight shift toward positive potentials (on average by $4.0 \pm 0.5 \mathrm{mV}$ at $V_{1 / 2} ; n=10$ ) after the addition of kurtoxin.

\section{Kurtoxin inhibition of L-type Ba currents}

We investigated kurtoxin inhibition of L-type $\mathrm{Ca}$ channel currents in thalamic neurons, using the same experimental conditions described in Figure $2 \mathrm{Cl}$ to enhance L-type $\mathrm{Ca}$ channel currents. The recorded cells were held at $-80 \mathrm{mV}$ to inactivate T-type Ca channels. They were exposed continuously to $\omega$-CgTX $(2.5 \mu \mathrm{M})$ and $\omega$-Aga-IVA (100-200 nM) to block N-type and P-type Ca channels and to the dihydropyridine agonist Bay $\mathrm{K}$ $8644(3 \mu \mathrm{M})$ to augment L-type Ca channel open probability.

In the experiment of Figure $7 A 1$, the application of $3 \mu \mathrm{M}$ Bay $\mathrm{K}$ 8644 increased the Ba currents elicited by a small depolarization to $-50 \mathrm{mV} 10$-fold, confirming that, at this potential, $>90 \%$ of the recorded $\mathrm{Ba}$ current was carried through L-type Ca channels. Consistent with an increase in L-type $\mathrm{Ca}$ channel open time (Nowycky et al., 1985), the agonist also slowed the deactivating tail currents seen on repolarization (Fig. 7A1, inset). Kurtoxin (200-250 nM) inhibited the Bay K 8644-enhanced L-type Ba currents on average by $74.1 \pm 3.7 \%$ (at $-45 \mathrm{mV} ; n=6$ ) as well as the Bay K 8644-enhanced tail currents recorded at $-70 \mathrm{mV}$.

This inhibition resembled that seen for T-type and $\mathrm{N}$-type $\mathrm{Ca}$ channel currents in being voltage-dependent and being accompanied by a slowing of activation (Fig. $7 A 1$, right). At $-45 \mathrm{mV}$ the kurtoxin almost doubled the time constant for current activation $\left(\tau_{\text {control }}=7.9 \pm 1.1\right.$ and $\left.\tau_{\text {kurtoxin }}=14.0 \pm 2.3 \mathrm{msec} ; n=12\right)$. The magnitude of current inhibition was more pronounced at negative test potentials (Fig. 7A1,A2). Kurtoxin inhibited $\sim 80 \%$ of the Bay $\mathrm{K} 8644$-enhanced Ba current recorded at $-45 \mathrm{mV}, \sim 25 \%$ of those
A1

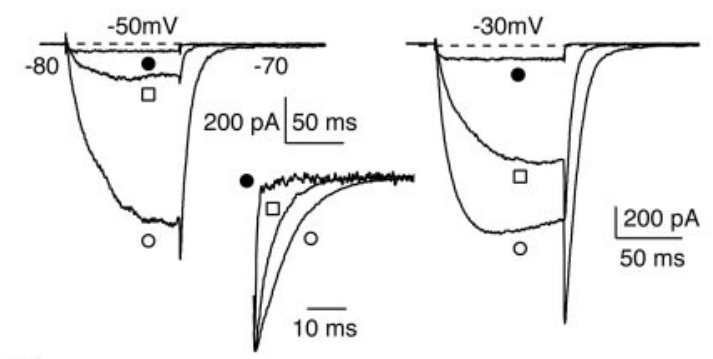

A2
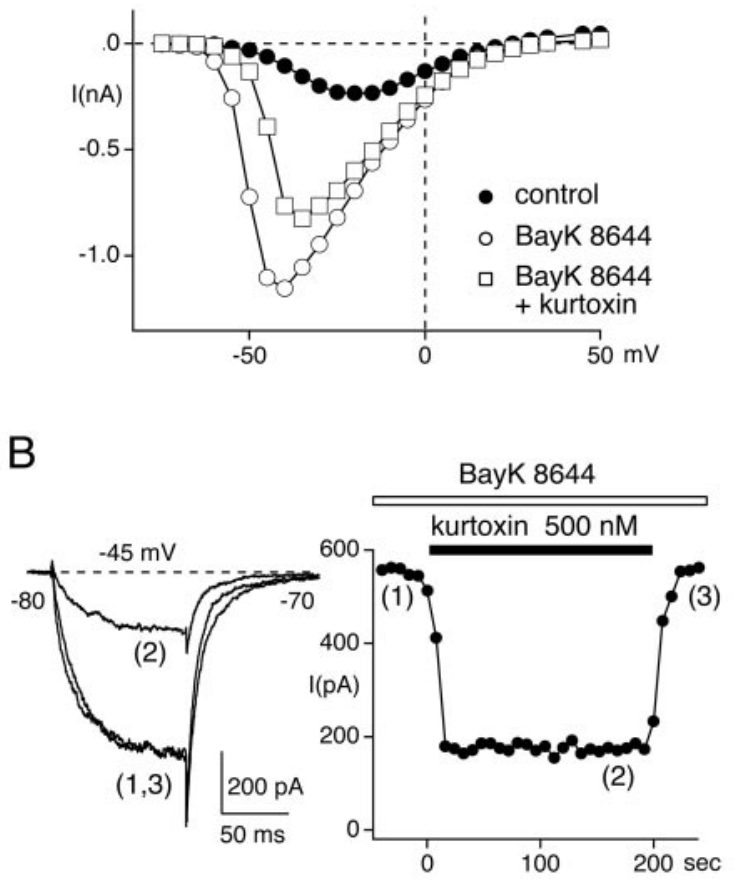

Figure 7. Kurtoxin inhibition of Bay K 8644-enhanced L-type Ba currents in thalamic neurons. $A 1$, Ba currents evoked by a $100 \mathrm{msec}$ depolarization applied from -80 to $-50 \mathrm{mV}$ (left) or to $-30 \mathrm{mV}$ (right) in control conditions $(\bullet)$, in the presence of $3 \mu \mathrm{M}$ Bay K $8644(\bigcirc)$, and in presence of $3 \mu \mathrm{M}$ Bay K 8644 plus $500 \mathrm{~nm}$ kurtoxin ( $\square)$. Inset, Normalized tail currents recorded at $-70 \mathrm{mV}$ in the same cell and in the same conditions after a test depolarization to $-50 \mathrm{mV}$. $A 2$, Current-voltage relationships obtained in the same cell in control conditions (-), in the presence of $3 \mu \mathrm{M}$ Bay K $8644(\bigcirc)$, and in presence of $3 \mu \mathrm{M}$ Bay K 8644 plus $500 \mathrm{~nm}$ kurtoxin $(\square)$. The data points represent the amplitude of the peak Ba current measured during 100-msec-long test depolarizations applied from $-80 \mathrm{mV}$ to various test potentials (ranging from -75 to +50 $\mathrm{mV}$, in $5 \mathrm{mV}$ increments). $B$, Reversibility of kurtoxin inhibition of Bay $\mathrm{K}$ 8644-enhanced L-type Ba currents in another thalamic neuron. The current traces illustrated on the left were obtained in the presence of $3 \mu \mathrm{M}$ Bay K 8644, after the addition of $3 \mu \mathrm{M}$ Bay K 8644 plus $500 \mathrm{~nm}$ kurtoxin, and after kurtoxin wash with $3 \mu \mathrm{M}$ Bay K 8644 still present. The corresponding time course is illustrated on the right. It represents the peak $\mathrm{Ba}$ current measured during 100-msec-long depolarizations applied from -80 to $-45 \mathrm{mV}$ every $6 \mathrm{sec}$. In $A 1-B$, the experiments were performed in the continuous presence of $2.5 \mu \mathrm{M} \omega$-CgTX and $200 \mathrm{~nm} \omega$-Aga-IVA and were performed in the minichamber (see Materials and Methods).

recorded at $-30 \mathrm{mV}$, and only $5 \%$ of the currents recorded at $-10 \mathrm{mV}$ (Fig. 7A2). Like T-type Ca channels, L-type Ca channels exposed to kurtoxin displayed faster deactivation (Fig. 7A1, inset). On average, the deactivation rate measured at $-70 \mathrm{mV}$ increased by $49 \pm 6 \%(n=12)$. 
Kurtoxin inhibition of Bay K 8644 was also fully reversible (Fig. 7B).

Although our data clearly demonstrate that kurtoxin inhibition of L-type Ba current is voltage-dependent, they could not be used for precise quantification. Kurtoxin facilitated the voltagedependent relief of P-type Ba current block by $\omega$-Aga-IVA (data not shown), which was manifest in the presence of kurtoxin at potentials as low as $0 \mathrm{mV}$. Unblocked P-type $\mathrm{Ca}$ channels thus may contribute to the currents recorded during large test depolarizations. Because of the prolongation of their open time (as in Fig. 4B), unblocked kurtoxin-modified P-type Ca channels also may contaminate the late phase of the Bay K 8644-enhanced tail currents. The classical approach, which uses the late component of the Bay K 8644-enhanced tail currents as a measure of L-type $\mathrm{Ca}$ channel activation, was therefore not applicable.

High-threshold Ba currents resistant to antagonists of L-type, N-type, and P-type Ca channels

In thalamic neurons as in other neurons (Eliot and Johnston, 1994; Penington and Fox, 1995; Randall and Tsien, 1995; Turner et al., 1995; Hilaire et al., 1997), a significant proportion of the total $\mathrm{Ba}$ current remained unaffected after blockade of P-type, $\mathrm{N}$-type, and L-type $\mathrm{Ca}$ channels. In the experiment of Figure 8, we used saturating concentrations of $2.5 \mu \mathrm{M}$ nimodipine, $2.5 \mu \mathrm{M}$ $\omega$-CgTX, and $1 \mu \mathrm{M} \omega$-Aga-IVA to maximize inhibition of L-type, $\mathrm{N}$-type, and P-type Ba currents. Within $30 \mathrm{~min}$ this combination of antagonists reduced the peak control current elicited at -35 $\mathrm{mV}$ by $\sim 90 \%$. The remaining Ba current showed a relatively low threshold for activation, because measurable activation already had occurred at $-50 \mathrm{mV}$ (Fig. $8 B$ ) plus significant inactivation during a $500 \mathrm{msec}$ test pulse (Fig. $8 C$ ) and fast deactivation kinetics (Fig. $8 A$, inset). It was, however, clearly distinct from T-type Ca channel currents (Fig. $8 C$, inset), which completely inactivated at holding potentials as negative as $-90 \mathrm{mV}$, showed a much lower threshold for activation of approximately $-80 \mathrm{mV}$ (Fig. $1 B$ ), and deactivated with slower kinetics (by a factor of $\sim 10$ at $-70 \mathrm{mV})$.

This remaining $\mathrm{Ba}$ current, isolated after a block of T-type, P-type, N-type, and L-type Ca channels, was inhibited partially by 500 nm kurtoxin (Fig. $8 A$ ). The magnitude of current inhibition showed clear voltage dependence, although less dramatic than that seen for other $\mathrm{Ca}$ channel types (Fig. $8 B$ ). For example, kurtoxin decreased the currents measured at $-40 \mathrm{mV}$ by $56.2 \pm$ $2.4 \%$ and those measured at $+10 \mathrm{mV}$ by $35.0 \pm 2.8 \%(n=3)$. Like T-type, L-type, N-type, and P-type Ba currents, this current activated with slower kinetics in the presence of kurtoxin; current deactivation, however, appeared to be unaffected (Fig. $8 A$, inset).

\section{DISCUSSION}

This study demonstrates that kurtoxin affects a large variety of $\mathrm{Ca}$ channels in mammalian neurons. Consistent with its potent blockade of $\alpha 1 \mathrm{G}$ and $\alpha 1 \mathrm{H}$ T-type Ca channels studied in Xenopus oocytes (Chuang et al., 1998), we find that kurtoxin inhibited low-threshold T-type $\mathrm{Ca}$ channel currents in thalamic neurons. However, it also targeted neuronal high-threshold $\mathrm{Ca}$ channels, including P-type, N-type, and L-type $\mathrm{Ca}$ channels, and others that still are unidentified pharmacologically. To our knowledge this is the first example of a gating modifier that acts with high potency on such a variety of neuronal low-threshold and highthreshold $\mathrm{Ca}$ channels.

Unlike other gating modifiers of $\mathrm{Ca}$ channels, such as grammatoxin (McDonough et al., 1997a) and $\omega$-Aga-IVA (Mintz et al.,
A

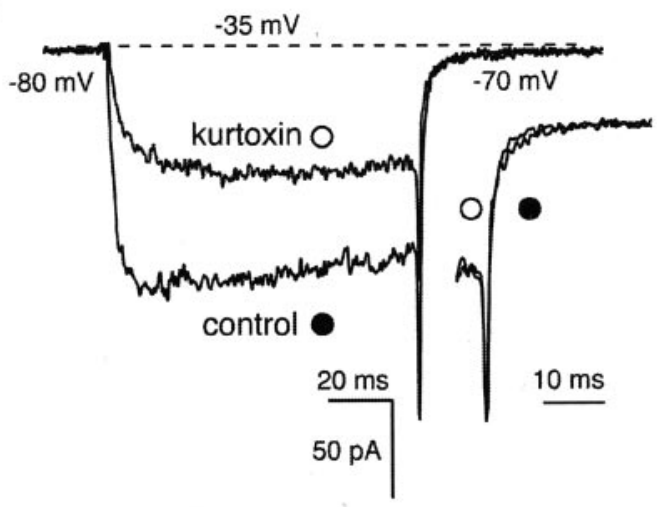

B
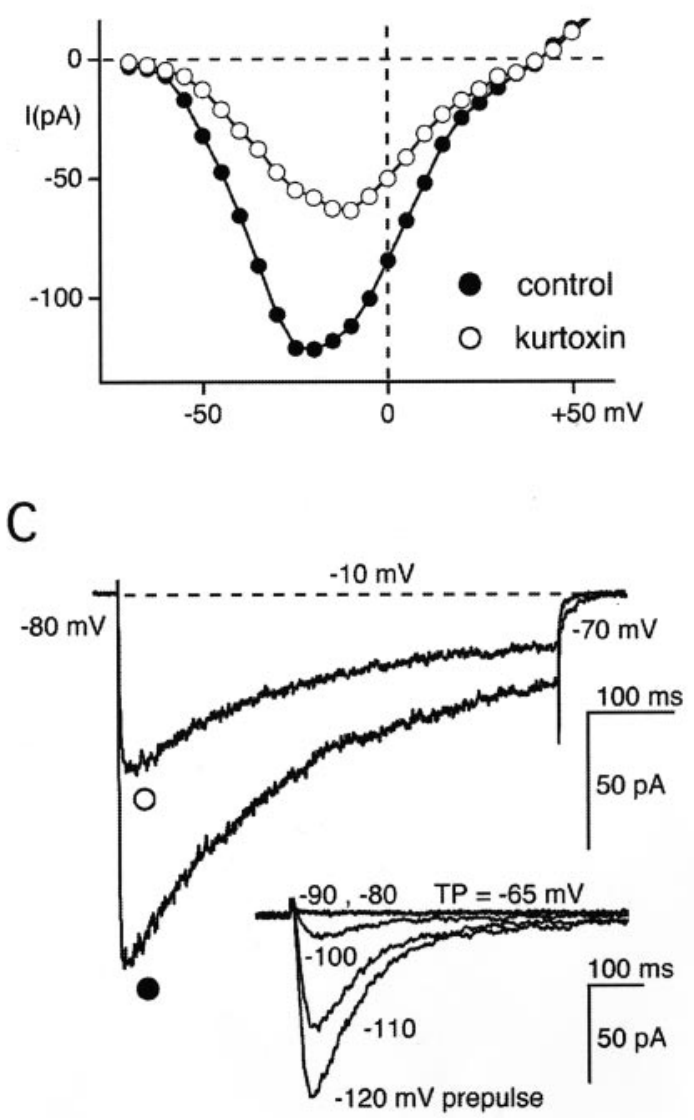

Figure 8. Kurtoxin inhibition of thalamic Ba currents that remained after the inactivation of T-type $\mathrm{Ba}$ currents and pharmacological blockade of L-type, N-type, and P-type Ca channels. $A$, Ba currents evoked by a 100 msec depolarization applied from -80 to $-35 \mathrm{mV}$ before $(0)$ and after (○) exposure to $500 \mathrm{~nm}$ kurtoxin for $10 \mathrm{~min}$. The inset illustrates the normalized tail currents recorded at $-70 \mathrm{mV}$. $B$, Current-voltage relationships obtained before (O) and after (O) the addition of $500 \mathrm{~nm}$ kurtoxin. The data points represent the amplitude of the peak Ba currents measured during a 100-msec-long depolarization applied every 6 sec from $-80 \mathrm{mV}$ to various test potentials (between -70 and $+50 \mathrm{mV}$, in $5 \mathrm{mV}$ increment). $C$, Time-dependent inactivation of the Ba current elicited by a 1-sec-long depolarization applied from -80 to $-10 \mathrm{mV}$ before $(\mathbf{)})$ and after $(\bigcirc)$ the application of $500 \mathrm{~nm}$ kurtoxin for $11 \mathrm{~min}$. Inset, Voltagedependent inactivation of the T-type $\mathrm{Ba}$ current recorded during a 500 msec test depolarization $(T P)$ to $-65 \mathrm{mV}$, which was conditioned by a 2-sec-long prepulse to various potentials (ranging from -120 to $-80 \mathrm{mV}$, in $10 \mathrm{mV}$ increments). All of the recordings in $A-C$ were obtained in the same thalamic neuron in the continuous presence of $1 \mu \mathrm{M} \omega$-Aga-IVA, 2.5 $\mu \mathrm{M} \omega$-CgTX, and $2.5 \mu \mathrm{M}$ nimodipine. 
1992b; Sather et al., 1993; McDonough et al., 1997b), kurtoxin produced very different sets of gating modifications in different $\mathrm{Ca}$ channel types. Kurtoxin inhibited T-type, L-type, and N-type $\mathrm{Ca}$ channels and facilitated P-type $\mathrm{Ca}$ channels. It accelerated deactivation in T-type and L-type $\mathrm{Ca}$ channels, slowed it in P-type Ca channels, and left it unaffected in N-type Ca channels.

These unexpected findings rule out the use of kurtoxin for functional studies of T-type Ca channels. Still, the variety of gating alterations it promotes is unique and may lead to new insights on how gating modifiers interact with voltage-gated $\mathrm{Ca}$ channels.

\section{Determination of kurtoxin potency}

We measured steady-state current reduction (for T-type, N-type, and L-type Ba currents) and increases in activation time constants (for P-type Ba currents) to evaluate the affinity of kurtoxin for each channel type (see Materials and Methods). The resulting dose-response curves were described well by hyperbolic functions, suggesting a bimolecular binding. Their fits yielded values of $50 \mathrm{~nm}$ (T-type), $15 \mathrm{~nm}$ (P-type), $460 \mathrm{~nm}$ (N-type), and $70 \mathrm{~nm}$ (L-type $\mathrm{Ba}$ currents) as respective dissociation constants $\left(K_{\mathrm{D}}\right.$ values) for kurtoxin.

Although imprecise, these numbers are informative. The potency for kurtoxin inhibition of native T-type $\mathrm{Ca}$ channels is comparable with that estimated for $\alpha 1 \mathrm{G} \mathrm{Ca}$ channels (15 nM) (Chuang et al., 1998). The kinetics, however, are quite different, because the off rate for kurtoxin binding to thalamic T-type $\mathrm{Ca}$ channels was $\sim 20$ times faster than that seen in $\alpha 1 \mathrm{G} \mathrm{Ca}$ channels. Kurtoxin modulation of P-type, L-type, and even N-type Ca channels was surprisingly potent, considering that concentrations as high as $350 \mathrm{~nm}$ have no effect on $\alpha 1 \mathrm{~A}, \alpha 1 \mathrm{~B}, \alpha 1 \mathrm{C}$, and $\alpha 1 \mathrm{E} \mathrm{Ca}$ channels (Chuang et al., 1998). We do not know whether this discrepancy reflects differences in the primary structure of native neuronal $\mathrm{Ca}$ channels and $\mathrm{Ca}$ channel clones expressed in Xenopus oocytes, distinct post-translational modifications, or their association with different auxiliary subunits.

\section{Association and dissociation kinetics}

As described in Materials and Methods, accurate measurements of kurtoxin on rate constants were impaired in our recording conditions (because of toxin nonspecific binding to glass capillaries or its nonhomogeneous application into the minichamber). Nevertheless, the time courses depicted in the figures illustrate the reversibility of kurtoxin effects and provide reasonable estimates of the toxin off rate. Except for N-type Ca channel current, the effects of kurtoxin were fully reversible, and current recovery followed simple monoexponential time courses. These results yielded off rate time constants of $\sim 13 \mathrm{sec}$ (T-type), $51 \mathrm{sec}$ (Ptype), $15 \mathrm{sec}$ (L-type), and $20 \mathrm{sec}$ (for N-type Ba currents).

Kurtoxin inhibition of N-type Ba currents showed complex kinetics that were well described by the sum of two exponential functions. Current recovery followed a monoexponential time course, but its magnitude was voltage-dependent. Although currents elicited by small test potentials returned to their control values after a wash of kurtoxin, currents measured at more positive potentials recovered only partially. These findings may reflect the structural heterogeneity of N-type $\mathrm{Ca}$ channels in sympathetic neurons. A subtype (possibly $\alpha 1 \mathrm{~B}_{\Delta \mathrm{ET}}$ variants) may carry the small current component that was inhibited slowly and irreversibly by kurtoxin (Lin et al., 1997). Another (possibly $\alpha 1 \mathrm{~B}_{+\mathrm{ET}}$ variants), with a lower threshold for activation, may carry the larger component that was inhibited rapidly and reversibly by kurtoxin (Lin et al., 1997). Alternatively, two kurtoxin molecules may bind to a single $\mathrm{N}$-type $\mathrm{Ca}$ channel with a first reversible step and a second irreversible one (Hess et al., 1975).

\section{Gating modifications}

\section{Activation and deactivation}

Kurtoxin modified T-type and L-type Ca channel currents by promoting slower activation and faster deactivation and by reducing steady-state currents. These effects were voltage-dependent. They resemble $\omega$-Aga-IVA inhibition of P-type $\mathrm{Ca}$ channels in Purkinje neurons and might be explained, similarly, by the stabilization of closed states (McDonough et al., 1997b). Toxin-bound channels then require larger depolarizations to gate into the open state. An expected corollary to these observations is the destabilization of kurtoxin binding to open channels. It will be interesting to see whether trains of large depolarizations increase the rate of kurtoxin unbinding as they do to $\omega$-Aga-IVA binding to P-type Ca channels. During the brief depolarizations that have been tested so far, there was no indication of kurtoxin unbinding from $\mathrm{T}$ - and L-type Ca channels.

In Purkinje neurons the kurtoxin also decreased the rate of P-type current activation and reduced currents recorded at negative test potentials, shifting the activation voltage dependence toward more positive potentials. All of these effects are consistent with a stabilization of closed states. Kurtoxin, however, produced other gating modifications in P-type $\mathrm{Ca}$ channels, because it clearly facilitated their steady-state currents and slowed their deactivation. The prolongation of P-type Ba tail currents suggests an increase in the open time of toxin-bound channels. We do not know whether this increase fully accounts for the steady-state current facilitation observed during large test pulses because it was contaminated with current run-up. Run-up was clearly different from the gating modifications produced by kurtoxin. It occurred by simple and irreversible scaling of the current amplitude, with no change in activation and deactivation kinetics. Its presence, however, impeded the true measure of steady-state current facilitation by kurtoxin.

Kurtoxin inhibition of N-type Ca channel currents was qualitatively different. As in other channel types, kurtoxin slowed activation, but at the resolution of our recordings it had no apparent effect on channel deactivation. Current reduction at steady state was also voltage-dependent, but to a much smaller extent. Current inhibition was also much less potent. Such differences are striking considering that N-type and P-type Ca channels are likely to be highly homologous (Williams et al., 1992; Berrow et al., 1997; Bourinet et al., 1999). These results imply that a limited number of amino acid substitutions (Fig. 9) may alter completely the nature of kurtoxin interaction with these channels, leading to opposite effects on gating.

\section{Inactivation}

Kurtoxin belongs to the family of $\alpha$-scorpion toxins, which slow inactivation of voltage-gated $\mathrm{Na}$ channels (Catterall, 1980) by inhibiting their transition from open to inactivated state without changing their activation (Wang and Strichartz, 1985). Kurtoxin, however, consistently slowed activation in parallel to its effect on inactivation. Both effects are seen for voltage-gated $\mathrm{Na}$ currents (Chuang et al., 1998), T-type Ba currents (Fig. 3), and the currents that remained after a blockade of P-type, L-type, and $\mathrm{N}$-type Ca channels (Fig. 8). In the case of T-type Ba currents the similar magnitudes of kurtoxin effects on inactivation and activation suggest that kurtoxin may act simply by reducing the number 


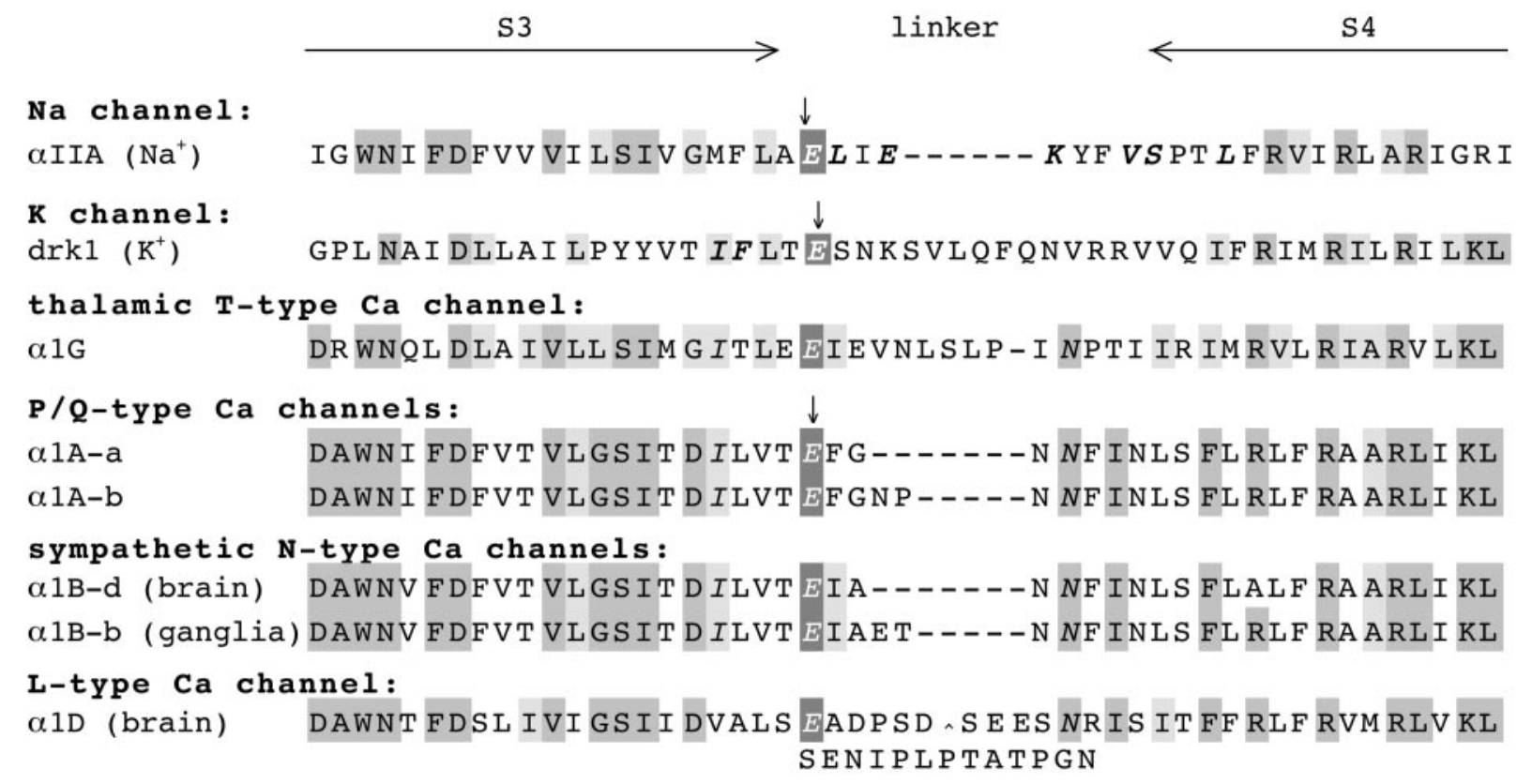

Figure 9. Sequence comparison of the domain IV S3-S4 linker in different voltage-gated ion channels. Dark and light boxes highlight the sequence identity between high-threshold $(\alpha 1 \mathrm{~A}, \alpha 1 \mathrm{~B}, \alpha 1 \mathrm{D})$ and low-threshold $(\alpha 1 \mathrm{G}) \mathrm{Ca}$ channels. Amino acids in bold contribute to the high-affinity binding of gating modifiers (see Discussion). Among those, note the glutamate indicated by arrows that is common to all of the voltage-gated ion channel clones that are represented here. The illustrated sequences are those of $\alpha$ IIA Na channels (Auld et al., 1988), drk1 K channels (Frech et al., 1989), $\alpha 1 \mathrm{G}$ T-type Ca channels (Perez-Reyes et al., 1998), $\alpha 1$ A-a, $\alpha 1$ A-b (Bourinet et al., 1999), $\alpha 1$ B-b, $\alpha 1$ B-d (Lin et al., 1997), and $\alpha 1 D$ (Snutch et al., 1990) Ca channels.

of open channels available for inactivation (Kuo and Yang, 2001). We have not examined the effects of kurtoxin on the inactivation of high-threshold $\mathrm{Ca}$ channels because this process was not fully reversible, especially for P-type Ca channels (Regan, 1991), in our recording conditions.

\section{Kurtoxin binding sites}

Because kurtoxin affects both voltage-gated $\mathrm{Na}$ and $\mathrm{T}$-type $\mathrm{Ca}$ channels, it has been proposed that kurtoxin recognizes a motif common to these channel types at a site located in the S3-S4 linker of domain IV close to the voltage sensor (Chuang et al., 1998). This hypothesis is particularly attractive because the same (or equivalent) channel region appears to be critical for highaffinity binding of other gating modifiers to voltage-gated $\mathrm{K}$ and Ca channels (Fig. 9). For example, the substitution of a particular glutamate (in position 1613) with neutral amino acids weakens binding of the $\alpha$-scorpion toxin $\mathrm{V}$ from Leiurus quinquestriatus (LqTX) to Na channels (Rogers et al., 1996), whereas its equivalent, in Shab (drk1) K channels, appears to be critical for the binding of hanatoxin and grammotoxin (Li-Smerin and Swartz, 1998, 2000) and, in Ca channels, for the high-affinity binding of $\omega$-Aga-IVA (Winterfield and Swartz, 2000).

In this context it is interesting to see that kurtoxin interfered noticeably with $\omega$-Aga-IVA inhibition of P-type Ca channels in Purkinje neurons. Kurtoxin diminished the magnitude of P-type Ba current block by $\omega$-Aga-IVA and slowed the time course of this inhibition. These effects suggest significant overlap between the binding sites for each toxin, and, because $\omega$-Aga-IVA binding has been mapped to the S3-S4 linker of domain IV (Winterfield and Swartz, 2000), they identify this region as one likely target for kurtoxin binding to P-type $\mathrm{Ca}$ channels.

We do not know whether kurtoxin binds to domain IV S3-S4 linker in T-type, L-type, and $\mathrm{N}$-type $\mathrm{Ca}$ channels. This question is of particular interest in the case of $\mathrm{N}$-type $\mathrm{Ca}$ channels for which the response to kurtoxin differs dramatically from that of P-type Ca channels despite their structural similarity (Fig. 9).

Our results suggest that kurtoxin is suited ideally for structural studies of voltage-dependent gating. Once conditions are identified for the expression of $\mathrm{Ca}$ channel clones that mimic the diversity of native $\mathrm{Ca}$ channels in their response to kurtoxin, this gating modifier may provide a powerful approach to the identification of key mechanisms of activation and deactivation in voltage-gated $\mathrm{Ca}$ channels.

\section{REFERENCES}

Aosaki T, Kasai H (1989) Characterization of two kinds of high-voltageactivated $\mathrm{Ca}$ channel currents in chick sensory neurons. Differential sensitivity to dihydropyridines and $\omega$-conotoxin GVIA. Pflügers Arch 414:150-156.

Auld VJ, Goldin AL, Krafte DS, Marshall J, Dunn JM, Catterall WA, Lester HA, Davidson N, Dunn RJ (1988) A rat brain $\mathrm{Na}^{+}$channel alpha subunit with novel gating properties. Neuron 1:449-461.

Berrow NS, Brice NL, Tedder I, Page KM, Dolphin AC (1997) Properties of cloned rat $\alpha 1 \mathrm{~A}$ calcium channels transiently expressed in the COS-7 cell line. Eur J Neurosci 9:739-748.

Boland LM, Morrill JA, Bean BP (1994) $\omega$-Conotoxin block of calcium channels in frog and rat sympathetic neurons. J Neurosci 14:5011-5027.

Bourinet E, Soong TW, Sutton K, Slaymaker S, Mathews E, Monteil A, Zamponi GW, Nargeot J, Snutch TP (1999) Splicing of $\alpha 1$ A subunit gene generates phenotypic variants of P-and Q-type calcium channels. Nat Neurosci 2:407-415.

Cahalan MD (1975) Modification of sodium channel gating in frog myelinated nerve fibres by Centruroides sculpturatus scorpion venom. J Physiol (Lond) 244:511-534.

Carbone E, Lux HD (1984) A low voltage-activated, fully inactivating Ca channel in vertebrate sensory neurons. Nature 310:501-502.

Catterall WA (1980) Neurotoxins that act on voltage-sensitive sodium channels in excitable membranes. Annu Rev Pharmacol Toxicol 20:15-43.

Chuang RS, Jaffe H, Cribbs L, Perez-Reyes E, Swartz KJ (1998) Inhibition of T-type voltage-gated calcium channels by a new scorpion toxin. Nat Neurosci 1:668-674.

Crunelli V, Lightowler S, Pollard CE (1989) A T-type $\mathrm{Ca}^{2+}$ current underlies low-threshold $\mathrm{Ca}^{2+}$ potentials in cells of the cat and rat lateral geniculate nucleus. J Physiol (Lond) 413:543-561.

Destexhe A, Neubig M, Ulrich D, Huguenard J (1998) Dendritic low- 
threshold calcium currents in thalamic relay cells. $\mathrm{J}$ Neurosci 18:3574-3588.

Eliot LS, Johnston D (1994) Multiple components of calcium current in acutely dissociated dentate gyrus granule neurons. J Neurophysiol 72:762-777.

Ellinor PT, Zhang JF, Horne WA, Tsien RW (1994) Structural determinants of the blockade of N-type calcium channels by a peptide neurotoxin. Nature 372:272-275.

Frech GC, Van Dongen AM, Schuster G, Brown AM, Joho RH (1989) A novel potassium channel with delayed rectifier properties isolated from rat brain by expression cloning. Nature 340:642-645.

Gorelova N, Reiner PB (1996) Role of the afterhyperpolarization in control of discharge properties of septal cholinergic neurons in vitro. J Neurophysiol 75:695-706.

Hamill OP, Marty A, Neher E, Sakmann B, Sigworth FJ (1981) Improved patch-clamp techniques for high-resolution current recording from cells and cell-free membrane patches. Pflügers Arch 391:85-100.

Herrington J, Bookman RJ (1994) PULSE CONTROL v4.0: IGOR XOPS for patch-clamp data acquisition and capacitance measurements. Miami, FL: University of Miami.

Hess GP, Bulger JE, Fu JL, Hindy EF, Silberstein RJ (1975) Allosteric interactions of the membrane-bound acetylcholine reception: kinetic studies with $\alpha$-bungarotoxin. Biochem Biophys Res Commun 64:1018-1027.

Hess P, Lansman JB, Tsien RW (1984) Different modes of Ca channel gating behaviour favoured by dihydropyridine $\mathrm{Ca}$ agonists and antagonists. Nature 311:538-544.

Hilaire C, Diochot S, Desmadryl G, Richard S, Valmier J (1997) Toxinresistant calcium currents in embryonic mouse sensory neurons. Neuroscience 80:267-276.

Hillyard DR, Monje VD, Mintz IM, Bean BP, Nadasdi L, Ramachandran J, Miljanich G, Azimi-Zoonooz A, McIntosh JM, Cruz LJ (1992) A new Conus peptide ligand for mammalian presynaptic $\mathrm{Ca}^{2+}$ channels. Neuron 9:69-77.

Hirsch JC, Burnod Y, Korn H (1985) Dorsolateral geniculate neurons in vitro: reduced postsynaptic excitability following repetitive activation of the optic tract. Neurosci Lett 58:151-156.

Huguenard JR (1996) Low-threshold calcium currents in central nervous system neurons. Annu Rev Physiol 58:329-348.

Jahnsen H, Llinás R (1984) Ionic basis for the electro-responsiveness and oscillatory properties of guinea-pig thalamic neurones in vitro. J Physiol (Lond) 349:227-247.

Jones SW, Marks TN (1989) Calcium currents in bullfrog sympathetic neurons. I. Activation kinetics and pharmacology. J Gen Physiol 94:151-167.

Kammermeier PJ, Jones SW (1997) High-voltage-activated calcium currents in neurons acutely isolated from the ventrobasal nucleus of the rat thalamus. J Neurophysiol 77:465-475.

Kuo CC, Yang S (2001) Recovery from inactivation of T-type $\mathrm{Ca}^{2+}$ channels in rat thalamic neurons. J Neurosci 21:1884-1892.

Lambert RC, McKenna F, Maulet Y, Talley EM, Bayliss DA, Cribbs LL, Lee JH, Perez-Reyes E, Feltz A (1998) Low-voltage-activated Ca ${ }^{2+}$ currents are generated by members of the CavT subunit family $(\alpha 1 \mathrm{G} / \mathrm{H})$ in rat primary sensory neurons. J Neurosci 18:8605-8613.

Lampe RA, Defeo PA, Davison MD, Young J, Herman JL, Spreen RC, Horn MB, Mangano TJ, Keith RA (1993) Isolation and pharmacological characterization of $\omega$-grammotoxin SIA, a novel peptide inhibitor of neuronal voltage-sensitive calcium channel responses. Mol Pharmacol 44:451-460.

Lee JH, Daud AN, Cribbs LL, Lacerda AE, Pereverzev A, Klockner U, Schneider T, Perez-Reyes E (1999) Cloning and expression of a novel member of the low voltage-activated T-type calcium channel family. J Neurosci 19:1912-1921.

Lin Z, Haus S, Edgerton J, Lipscombe D (1997) Identification of functionally distinct isoforms of the N-type $\mathrm{Ca}^{2+}$ channel in rat sympathetic ganglia and brain. Neuron 18:153-166.

Li-Smerin Y, Swartz KJ (1998) Gating modifier toxins reveal a conserved structural motif in voltage-gated $\mathrm{Ca}^{2+}$ and $\mathrm{K}^{+}$channels. Proc Natl Acad Sci USA 95:8585-8589.

Li-Smerin Y, Swartz KJ (2000) Localization and molecular determinants of the hanatoxin receptors on the voltage-sensing domain of a $\mathrm{K}^{+}$ channel. J Gen Physiol 115:673-684.

Llinás R, Sugimori M, Lin JW, Cherksey B (1989) Blocking and isolation of a calcium channel from neurons in mammals and cephalopods utilizing a toxin fraction (FTX) from funnel-web spider poison. Proc Natl Acad Sci USA 86:1689-1693.

MacKinnon R, Miller C (1988) Mechanism of charybdotoxin block of the high-conductance, $\mathrm{Ca}^{2+}$-activated $\mathrm{K}^{+}$channel. J Gen Physiol 91:335-349.

Magee JC, Carruth M (1999) Dendritic voltage-gated ion channels regulate the action potential firing mode of hippocampal CA1 pyramidal neurons. J Neurophysiol 82:1895-1901.
McCleskey EW, Fox AP, Feldman DH, Cruz LJ, Olivera BM, Tsien RW Yoshikami D (1987) $\omega$-Conotoxin: direct and persistent blockade of specific types of calcium channels in neurons but not muscle. Proc Natl Acad Sci USA 84:4327-4331.

McCobb DP, Beam KG (1991) Action potential waveform voltage-clamp commands reveal striking differences in calcium entry via low and high voltage-activated calcium channels. Neuron 7:119-127.

McDonough SI, Swartz KJ, Mintz IM, Boland LM, Bean BP (1996) Inhibition of calcium channels in rat central and peripheral neurons by $\omega$-conotoxin MVIIC. J Neurosci 16:2612-2623.

McDonough SI, Lampe RA, Keith RA, Bean BP (1997a) Voltagedependent inhibition of N- and P-type calcium channels by the peptide toxin $\omega$-grammotoxin-SIA. Mol Pharmacol 52:1095-1104.

McDonough SI, Mintz IM, Bean BP (1997b) Alteration of P-type calcium channel gating by the spider toxin $\omega$-Aga-IVA. Biophys $\mathrm{J}$ 72:2117-2128.

Mintz IM, Venema VJ, Swiderek KM, Lee TD, Bean BP, Adams ME (1992a) P-type calcium channels blocked by the spider toxin $\omega$-AgaIVA. Nature 355:827-829.

Mintz IM, Adams ME, Bean BP (1992b) P-type calcium channels in rat central and peripheral neurons. Neuron 9:85-95.

Nowycky MC, Fox AP, Tsien RW (1985) Long-opening mode of gating of neuronal calcium channels and its promotion by the dihydropyridine calcium agonist Bay K 8644. Proc Natl Acad Sci USA 82:2178-2182.

Paxinos G, Watson C (1986) The rat brain in stereotaxic coordinates, 2nd Ed. San Diego: Academic.

Penington NJ, Fox AP (1995) Toxin-insensitive Ca current in dorsal raphe neurons. J Neurosci 15:5719-5726.

Perez-Reyes E, Cribbs LL, Daud A, Lacerda AE, Barclay J, Williamson MP, Fox M, Rees M, Lee JH (1998) Molecular characterization of a neuronal low-voltage-activated T-type calcium channel. Nature 391:896-900.

Pfrieger FW, Veselovsky NS, Gottmann K, Lux HD (1992) Pharmacological characterization of calcium currents and synaptic transmission between thalamic neurons in vitro. J Neurosci 12:4347-4357.

Plummer MR, Logothetis DE, Hess P (1989) Elementary properties and pharmacological sensitivities of calcium channels in mammalian peripheral neurons. Neuron 2:1453-1463.

Randall A, Tsien RW (1995) Pharmacological dissection of multiple types of $\mathrm{Ca}^{2+}$ channel currents in rat cerebellar granule neurons. J Neurosci 15:2995-3012.

Regan LJ (1991) Voltage-dependent calcium currents in Purkinje cells from rat cerebellar vermis. J Neurosci 11:2259-2269.

Rogers JC, Qu Y, Tanada TN, Scheuer T, Catterall WA (1996) Molecular determinants of high affinity binding of $\alpha$-scorpion toxin and sea anemone toxin in the S3-S4 extracellular loop in domain IV of the $\mathrm{Na}^{+}$channel alpha subunit. J Biol Chem 271:15950-15962.

Sather WA, Tanabe T, Zhang JF, Mori Y, Adams ME, Tsien RW (1993) Distinctive biophysical and pharmacological properties of class A (BI) calcium channel $\alpha 1$ subunits. Neuron 11:291-303.

Scroggs RS, Fox AP (1992) Multiple $\mathrm{Ca}^{2+}$ currents elicited by action potential waveforms in acutely isolated adult rat dorsal root ganglion neurons. J Neurosci 12:1789-1801.

Snutch TP, Leonard JP, Gilbert MM, Lester HA, Davidson N (1990) Rat brain expresses a heterogeneous family of calcium channels. Proc Natl Acad Sci USA 87:3391-3395.

Stocker JW, Nadasdi L, Aldrich RW, Tsien RW (1997) Preferential interaction of $\omega$-conotoxins with inactivated $\mathrm{N}$-type $\mathrm{Ca}^{2+}$ channels. J Neurosci 17:3002-3013.

Takahashi T, Momiyama A (1993) Different types of calcium channels mediate central synaptic transmission. Nature 366:156-158

Tottene A, Moretti A, Pietrobon D (1996) Functional diversity of P-type and R-type calcium channels in rat cerebellar neurons. J Neurosci 16:6353-6363.

Turner TJ, Lampe RA, Dunlap K (1995) Characterization of presynaptic calcium channels with $\omega$-conotoxin-MVIIC and $\omega$-grammotoxinSIA: role for a resistant calcium channel type in neurosecretion. Mol Pharmacol 47:348-353.

Usowicz MM, Sugimori M, Cherksey B, Llinás R (1992) P-type calcium channels in the somata and dendrites of adult cerebellar Purkinje cells. Neuron 9:1185-1199.

Wang GK, Strichartz G (1985) Kinetic analysis of the action of Leiurus scorpion $\alpha$-toxin on ionic currents in myelinated nerve. J Gen Physiol 86:739-762.

Williams ME, Brust PF, Feldman DH, Patthi S, Simerson S, Maroufi A, McCue AF, Velicelebi G, Ellis SB, Harpold MM (1992) Structure and functional expression of an $\omega$-conotoxin-sensitive human N-type calcium channel. Science 257:389-395.

Winterfield JR, Swartz KJ (2000) A hot spot for the interaction of gating modifier toxins with voltage-dependent ion channels. J Gen Physiol $116: 637-644$ 